\title{
Toward science-oriented validations of coastal altimetry: Application to the Ligurian Sea
}

\author{
Meloni M. ${ }^{1,}{ }^{*}$, Bouffard J. ${ }^{2}$, Doglioli A.M. ${ }^{3}$, Petrenko A.A. ${ }^{3}$, Valladeau G. ${ }^{4}$
}

1 Serco, Via Sciadonna n.24, Frascati, Italy

2 ESA (European Space Agency), Earth Observation Directorate, Via Galileo Galilei, 2-00044 Frascati, Italy

${ }^{3}$ Aix Marseille Univ., Université de Toulon, CNRS, IRD, MIO UM 110, 13288, Marseille, France

${ }^{4}$ CLS (Collecte Localisation Satellites), 11 Rue Hermes, 31520 Ramonville-Saint-Agne, France

*Corresponding author : M. Meloni, email address : marco.meloni@serco.com

\begin{abstract}
:
This study is a preliminary contribution to the European Space Agency's efforts aimed at establishing reference in situ networks specifically targeted to validate coastal altimetry. For this purpose, we processed and cross-compared conjointly improved altimetry data and in situ measurements acquired over the Ligurian Sea - a coastal region of the Mediterranean characterised by complex, fine-scale and rapidly evolving oceanic features. We made use of several kinds of multi-sensor in situ observations located along SARAL and Jason-2 tracks. The main objectives of the study were to assess improved coastal oriented validation strategies, including the usage of a new in situ platform (Moving Vessel Profiler), while better understanding potential differences owing to physical content inconsistency and instrumental or data processing limitations. The results show remarkable agreements over spatial scales of few tens of kilometres, paving the way for the deployment of future in situ networks and the definition of science-oriented diagnostics targeted to assess the capability of present and future high-resolution altimetric missions in resolving small-scale physical features.
\end{abstract}

\section{Highlights}

- Validating coastal altimetry in fine-scale dynamics areas is challenging. Ad-hoc multi-platform validation approaches required. Measurements from the MVP are very promising for validating coastal altimetry. The combined use of collocated MVP, altimetry and ADCP appear to be relevant.

Keywords : Coastal altimetry, Mesoscale, Validation and verification, Northern current 
34 Even if coastal zones cover only $8 \%$ of the entire ocean surface of the earth (Stanev et

35 al., 2002), they play a crucial role for global ocean circulation, as it provides

36 dynamical boundary layers for physical, chemical and biological processes. Coastal

37 regions are characterised by complex ocean dynamics; they are often dominated by

38 small and rapidly evolving mesoscale/sub-mesoscale structures (hereafter "(sub-

39 )mesoscale"), which play a major role in the transport of heat, salt and

40 biogeochemical tracers (McGillicuddy et al., 1998; Levy and Martin, 2013;

41 Mahadevan, 2016) and significantly influence water-mass mixing and exchanges

42 between the continental shelf and the open ocean (Huthnance, 1995; Muller-Karger et

43 al., 2005). Despite their importance, the high spatial/temporal variability and

44 complexity associated with (sub-)mesoscale dynamics make them difficult to study

45 with sparse in situ observations (Nencioli et al., 2013), requiring the development of

46 modelling at kilometric (Thomas et al., 2008) and sub-kilometric horizontal space

47 grids (Gula et al., 2014; Shcherbina et al., 2013) as well as the use of high-resolution

48 satellite observations (Lehahn et al., 2007; Fu and Ferrarri, 2008; Bouffard et al.,

49 2014; $\mathrm{Hu}$ et al., 2011). The issue of characterising (sub-)mesoscale processes is

50 particularly critical over the coastal domain, where the local Rossby radius is smaller

51 than in the open-ocean (Hallberg, 2013). 
52 Over the last three decades, progress in satellite altimetry has contributed to revolutionising physical oceanography, enabling the global characterization of openocean large scale and mesoscale processes (Pascual et al., 2010, 2013; Fu et al., 2001). Satellite altimeters are particularly well adapted for observing open-ocean structures (Fu et al., 2010) and represent an invaluable source of data, providing repetitive views of phenomena unachievable by other means (Fu and Chelton, 2001). One of the main challenges for the next decade is the characterisation of fine-scale processes in the coastal domain (Cipollini et al., 2009). Achieving this goal requires not only the innovation of space-born instruments and processing techniques but also establishing ad-hoc validation approaches, allowing better assessment of potential improvements regarding the precision and accuracy of retrieved geophysical parameters. Increasingly more multi-disciplinary in situ data acquired by marine observatories and oceanographic campaigns are now being made available (Palacz et al., 2017) and can be used to derive quality indicators for coastal altimetry based on the assessment of along-track sea surface gradients complementary to the assessment of sea surface time series from tide gauges (Bonnefond et al., 2018). Here, we propose exploiting such in situ data resources to quantify the potential benefit of innovative coastal altimetry processing techniques for the characterization of smallscale ocean geostrophic currents.

Several previous studies have evaluated the capabilities of conventional pulse-limited $\mathrm{Ku}-\mathrm{Band}$ altimetry to observe mesoscale dynamics in semi-enclosed seas, such as the Mediterranean Sea (Vignudelli et al., 2005; Bouffard et al., 2008a, 2008b, 2011; Birol and Delebecque, 2014; Birol and Niño, 2015; Jebri et al., 2017). Despite significant advances, new coastal-oriented processing techniques require continuous optimisation and refinement by being systematically cross-compared with collocated 
multi-platform measurements. Over the last decade, several cruise campaigns using ship and glider measurements along with altimeter tracks have been carried out in the Western Mediterranean Sea (Ruiz et al., 2012). For example, in Ruiz et al.'s (2009) study, glider- and ship-based measurements were performed under an ENVISAT track in order to provide a mesoscale description of the Balearic Front. Coastal and mesoscale dynamics analysis using conventional altimetry and gliders have also been described by Bouffard et al. (2010, 2012) and Aulicino et al. (2018) over the Balearic Sea and the Algerian Basin respectively. More recently, significant improvements have been obtained as a result of the advent of new technologies, such as Ka-band measurements from SARAL (Verron et al., 2015; Troupin et al. 2015; Pascual et al., 2015) and SAR altimetry measurements from the CryoSat-2 and Sentinel-3 missions (Bonnefond et al., 2018; Pascual et al., 2017; Morrow et al., 2017; Dinardo et al., 2017; Heslop et al., 2017; Bouffard et al., 2017; Calafat et al., 2016).

The goal of the present paper is to go one step further in the fine cross-analysis of coastal altimetry data and in situ measurements by determining the potential source of disagreements due to measurement errors and data processing limitations with respect to expected differences arising from physical content inhomogeneity and in situ reference level issues. Here, we utilise both Moving Vessel Profiler (MVP) and Acoustic Doppler Current Profiler (ADCP) acquired during the OSCAHR (Observing Submesoscale Coupling at High Resolution, Doglioli, 2015) Campaign along SARAL and Jason-2 altimetric tracks. We focus our analysis on the impact assessment of coastal-oriented altimetry processing strategies specifically developed and tested with experimental high frequency PEACHI products (Valladeau et al., 2015). The obtained improvements are discussed with respect to regional $1 \mathrm{~Hz}$ AVISO Sea Level Anomaly products (http://aviso.altimetry.fr/). Two kinds of Mean 
102 Dynamic Topographies (MTDs) have been also used and analysed in order to 103 reconstruct Absolute Dynamic Topography (ADT).

104 After describing the study area and the characteristics of the in situ and space-based

105 datasets used, the derived absolute geostrophic currents are compared to both ADCP

106 and MVP measurements, which, in our knowledge, are used conjointly for the first

107 time to evaluate coastal altimetry strategies. The paper then focuses on the 108 quantitative and qualitative analysis of depicted ocean features, providing a critical

109 discussion on the limitations and uncertainty associated with each observing system.

1112 Study Areas

112 Although the issues addressed in this paper are of global relevance, its primary focus

113 is on the North-Western Mediterranean (NWMed) Sea with particular emphasis on

114 the Ligurian Sea area. Figure 1 shows the bathymetry of the selected area along with

115 altimetry tracks (black lines), in situ measurements and the general circulation 116 patterns.

117 The regional dynamics of the area is dominated by a cyclonic gyre circulation, the 118 northern part of which is known as the "Liguro-Provençal Current" (Millot, 1991, 119 1999) or the "Northern Current" (NC) (Millot and Taupier Letage, 2005). This slope 120 current arises from the merging of the eastern and western Corsica currents in the 121 Ligurian Basin. It then flows to the southwest along the continental slope until it 122 reaches the Balearic Sea. The NC exhibits a permanent surface density front between 123 the lighter coastal waters and the denser waters found offshore, generating a sea 124 surface high gradient in the across-shore direction.

125 Several numerical studies (Barrier et al., 2016; Zakardjan and Prieur, 1998) and 126 observations along the path of the $\mathrm{NC}$, such as hydrographic measurements from $\mathrm{R} / \mathrm{V}$ 
127 cruises and HF radar (Forget et al., 2006; Marmain et al., 2014) describe this current

128 as a complex dynamical feature marked by a large spectrum of spatial and temporal

129 scales of variability. The NC is relatively narrow $(\sim 30-75 \mathrm{~km})$ and its mean position

130 lies within $60 \mathrm{~km}$ off the coast (Petrenko, 2003). The core of the NC is stronger and

131 located about $10-40 \mathrm{~km}$ away from the coast in winter, while it is less defined and

132 further offshore in late summer and early fall (Birol et al., 2010; Piterbarg et al., 133 2014; Declerck et al., 2016).

134 Glider transects across the NC have been performed in the Ligurian Sea, such as in

135 Cyr et al. (2017) and during the MOOSE project (Quentin et al., 2013). Two different

136 parts constitute the main cyclonic circulation over this area: a small recirculation

137 centred on the grey arrow in Figure 1 and a second one in the southwest separated by

138 a local minimum in current intensity (Marrec et al., 2018). The ADT signature

139 associated with this fine-scale circulation can be potentially observed using satellite

140 altimetry measurements (Bouffard, 2010). However, monitoring coastal dynamics

141 from space is still challenging because of the numerous instrumental and geophysical

142 limitations in addition to the fact that the altimeter footprints may encounter the 143 coastline, corrupting the raw along-track remote-sensed signal (Anzenhofer et al., 144 1999; Strub, 2001). 

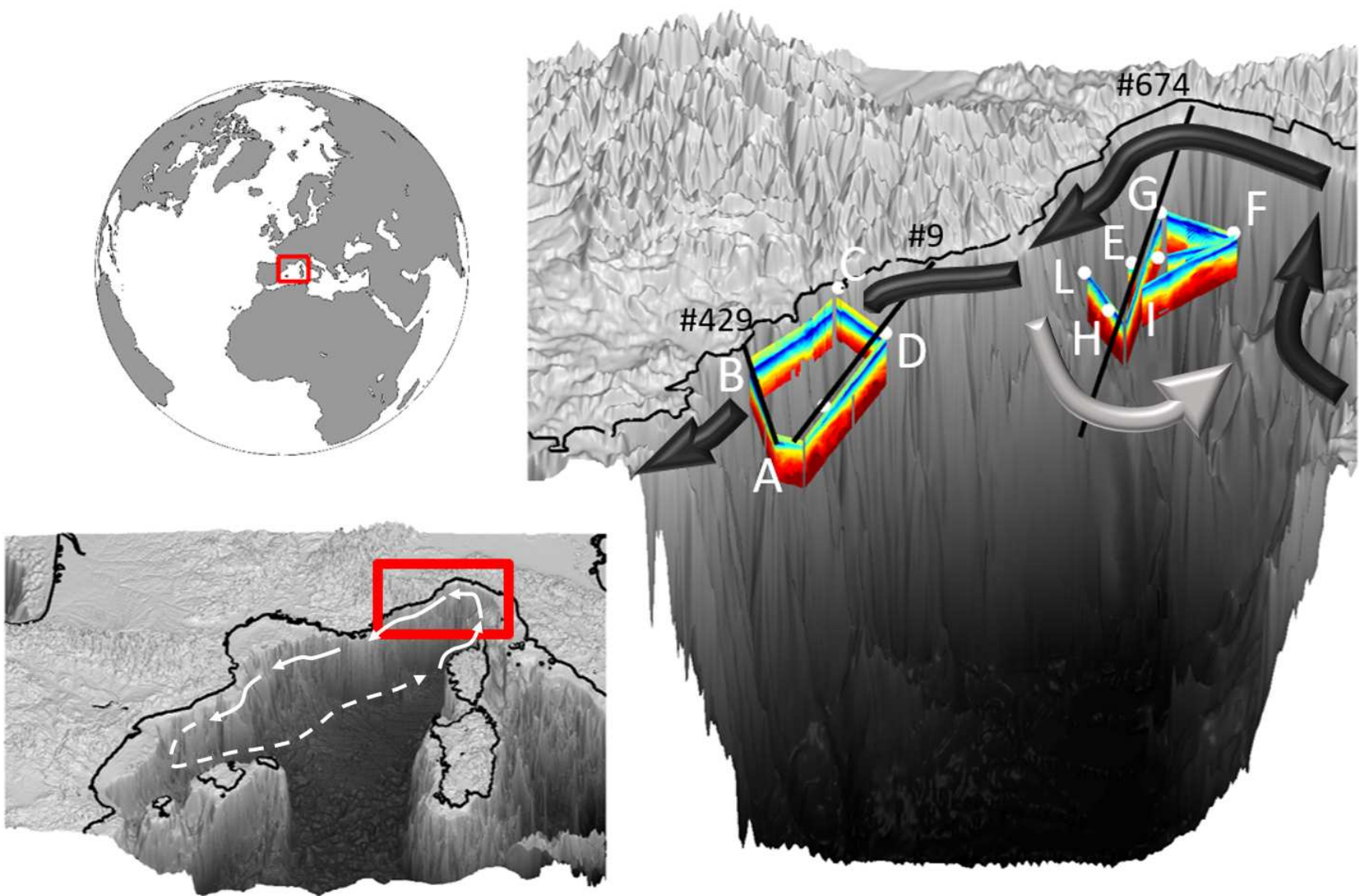

Figure 1 OSCAHR cruise transects (in letters) showing MVP vertical salinity profiles (coloured

\section{$151 \quad 3 \quad$ Data and Methods}

\section{$152 \quad 3.1 \quad$ In situ observations}

153 The in situ observations used in our study were acquired during the OSCAHR

154 campaign (Doglioli, 2015), whose scientific objectives included the characterisation

155 of a sub-mesoscale dynamical structure and study of its influence on the distribution

156 of biogenic elements and the structure and dynamics of the first trophic levels

157 (Marrec et al., 2018). The cruise strategy utilises an adaptive approach based on the 
near real-time analysis of both satellite data and numerical modelling in order to

159 identify the dynamical features of interest and track their evolution. Apart from its

160 main scientific objectives regarding (sub-)mesoscale physical/biochemistry coupling

161 the OSCAHR campaign also aims to validate new remote-sensing retrieval

162 techniques (altimetry, ocean colour, planktonic assemblage reconstruction) and high-

163 resolution numerical modelling. In particular, we performed in situ measurements

164 along three altimetric tracks shown in Figure 1 in the present study. The satellite and

165 vessel passages are summarised in Table 1.

166 The R/V Téthys II is equipped with a hull-mounted ADCP RDI Ocean Sentinel 75

$167 \mathrm{kHz}$; however, the methodology considered in this paper includes the usage of novel

168 platforms of observation for sampling the ocean sub-surface layer at a high spatial

169 and temporal frequency. In particular, we use a MVP200 equipped with a MSFFF I

170 (Multi-Sensor Free Fall Fish type I). A total of 448 casts were performed along a 366-

$171 \mathrm{~km}$ route (55 hours of effective work). During the free fall, for each cast,

172 measurements of temperature, salinity and pressure were performed with a temporal

173 resolution of $8-10 \mathrm{~min}$, corresponding to a spatial horizontal resolution of $\sim 1 \mathrm{~km}$.

174 The CTD (Conductivity Temperature and Depth) sensor mounted in the MVP towed

175 fish has the following precisions: $\pm 0.005\left[{ }^{\circ} \mathrm{C}\right]$ for temperature and $\pm 0.01[\mathrm{mS} \mathrm{cm}-1]$

176 for conductivity. The density is estimated using the TEOS-10 (Thermodynamic

177 Equation of Seawater) equation of state of seawater. Thereafter, temperature, salinity

178 and density fields were used to estimate the Dynamic Height (DH) with respect to an

179 arbitrary, no-motion reference level. This reference level is generally chosen to be at

180 the maximum depth reached by the probe. Following Pond et al., (1986):

181

182

$$
\mathrm{DH}=\int \delta(\mathrm{T}, \mathrm{S}, \mathrm{p}) \mathrm{dp}
$$


184 where:

$$
\delta(T, S, p)=\rho(T, S, p)^{-1}-\rho(0,35, p)^{-1}
$$

$187 \delta$ is the specific volume anomaly, i.e., the difference in volume between a unit mass

188 of water at temperature $\mathrm{T}$, salinity $\mathrm{S}$ and pressure $\mathrm{p}$ and a unit mass at the temperature $\mathrm{T}=0^{\circ} \mathrm{C}$, salinity $\mathrm{S}=35.0$ and pressure $\mathrm{p}$.

190 In a local Cartesian coordinate with $x$ axis pointing East, $y$ axis pointing North, the

191 geostrophic approximation is then applied to compute the MVP-derived current:

$$
V=\frac{f}{g} \cdot \frac{d h}{d x}
$$

193 where $\mathrm{f}$ is the Coriolis parameter, $\mathrm{g}$ is gravity $\left(9.8 \mathrm{~m} \mathrm{~s}^{-2}\right)$ and $\mathrm{h}$ is the $\mathrm{DH}$.

194 MVP-derived relative DH and geostrophic current (with respect to reference depth)

195 were compared with the geo-located SARAL and Jason-2 altimetry-derived absolute

196 ADT and currents (with respect to the geoid). As compared to ocean gliders, using

197 MVP has three main advantages: i) the probe performs free fall vertical profiles; ii)

198 the sampling rate is higher and iii) the planned route (e.g., the altimetric track) is

199 better followed, being the exact probe wed by the vessel. On the other hand, the main

200 limit is a lower maximum operating depth. Subsequently, to understand the impacts

201 of the reference depth and ageostrophic motions in the altimetry versus MVP 202 comparisons, ADCP measurements were also considered in this study. The ADCP 203 configuration used during the whole cruise included 60 cells, $8 \mathrm{~m}$ depth bins, an 204 ensemble average of $1^{\prime}$ and bottom tracking when possible (although most of the 205 cruise took place out of reach of the bottom). The depth range extends from $18.5 \mathrm{~m}$ to $206562.5 \mathrm{~m}$ with a vertically averaged error of $3.6 \mathrm{~cm} / \mathrm{s}$. 


\begin{tabular}{|c|c|c|c|c|c|c|}
\hline Trace & $\begin{array}{l}\text { Satellite } \\
\text { Passage }\end{array}$ & $\begin{array}{l}\text { Beginning } \\
\text { waypoint }\end{array}$ & $\begin{array}{l}\text { MVP } \\
\text { Start }\end{array}$ & $\begin{array}{l}\text { Ending } \\
\text { Waypoint }\end{array}$ & $\begin{array}{l}\text { MVP } \\
\text { end }\end{array}$ & $\begin{array}{l}\text { Time } \\
\text { Diff. }\end{array}$ \\
\hline Jason-2 \#9 & $\begin{array}{l}31 / 10 / 15 \\
16: 56\end{array}$ & D & $\begin{array}{l}30 / 10 / 15 \\
15: 30\end{array}$ & A & $\begin{array}{l}30 / 10 / 15 \\
23: 30\end{array}$ & $-21 \mathrm{~h}$ \\
\hline $\begin{array}{l}\text { SARAL } \\
\# 429\end{array}$ & $\begin{array}{l}30 / 10 / 15 \\
05: 02\end{array}$ & A & $\begin{array}{l}31 / 10 / 15 \\
01: 30\end{array}$ & B & $\begin{array}{l}01 / 11 / 15 \\
06: 30\end{array}$ & $+35 \mathrm{~h}$ \\
\hline $\begin{array}{l}\text { SARAL } \\
\# 674\end{array}$ & $\begin{array}{l}07 / 11 / 15 \\
18: 02\end{array}$ & G & $\begin{array}{l}03 / 11 / 15 \\
23: 00\end{array}$ & I & $\begin{array}{l}04 / 11 / 15 \\
03: 00\end{array}$ & $-89 \mathrm{~h}$ \\
\hline $\begin{array}{l}\text { SARAL } \\
\# 674\end{array}$ & $\begin{array}{l}07 / 11 / 15 \\
18: 02\end{array}$ & $\mathrm{H}$ & $\begin{array}{l}04 / 11 / 15 \\
23: 30\end{array}$ & G & $\begin{array}{l}05 / 11 / 15 \\
06: 00\end{array}$ & $-63 \mathrm{~h}$ \\
\hline
\end{tabular}

\subsection{Coastal altimetry}

211 In this paper, we used regional Mediterranean $1 \mathrm{~Hz}$ Jason-2 and SARAL Sea Level

212 Anomaly (SLA), defined as the difference between the observed sea surface height

213 and the mean sea level available and distributed by AVISO (User Handbook

214 Ssalto/DUACS, 2016) as well as the experimental high frequency PEACHI

215 (Prototype for Expertise on SARAL for Coastal, Hydrology and Ice) products

216 (Valladeau et al., 2015.). Some specific retracking algorithms, corrections, editing

217 procedures and MDT have been applied to these products and have been described 218 below.

\section{$219 \quad 3.2 .1 \quad$ Retracking}

220 One of the largest sources of errors in coastal altimetry is the inaccurate processing of

221 the return waveforms. A significant number of ocean return waveforms near the coast

222 indeed do not conform to the standard Brown model (Brown, 1997)), as they are 
223 affected by the noisier radar echoes from the land and/or calmer water contamination

224 (Vignudelli et al., 2011). Several studies addressed this issue in the coastal domain.

225 For example, Brooks et al. (1998) analysed the TOPEX waveforms obtained when

226 the altimeter transited from water to land and from land to water. They showed that

227 waveform retracking can be used to extend the altimeter-derived sea surface 228 topography several kilometres shoreward. Deng et al. (2002) investigated the 229 behaviour of ERS-2 and POSEIDON altimeter waveform data in the Australian 230 coastal region and mapped a boundary, located approximately $22 \mathrm{~km}$ from the coast 231 of Australia, within which the altimeter range may be poorly estimated. Deng and 232 Featherstone (2006) developed a retracking system that includes least-squares fitting 233 of a five-parameter model and a threshold method applied to altimeter waveforms 234 around Australia. In addition to the previously mentioned studies, Gomez-Enri et al. 235 (2009) developed an experimental mixed Brown-specular retracker for the specular 236 peak embedded within a Brown-type ocean waveform. More recently, new coastal 237 retracking strategies have been developed and successfully applied, such as the ALES 238 (Adaptive Leading Edge Subwaveform) (Passaro et al., 2014) and ALES+ (Passaro et 239 al., 2018), potentially applicable to all pulse-limited altimetry missions over both 240 open and coastal ocean with the same accuracy.

241 In this study, three types of retracking algorithms have been applied to PEACHI 242 products. Their main characteristics are described below:

243 i. Red3 PISTACH (Prototype Innovant de Système de Traitement pour les Applications Côtières et l'Hydrologie) (Coastal and Hydrology Altimetry product handbook, 2010): This algorithm selects an analysis window centred on the main leading edge of the waveform and retracking parameters in this reduced window $[-10 ;+20$ samples $]$ with a Maximum 
Likelihood Estimator solving for 3 parameters (range, amplitude and Sigma composite).

ii. $\quad$ MLE4 (Maximum Likelihood Estimator) (Amarouche et al., 2004): This decay, is held fixed.

\subsubsection{Geophysical Corrections}

268 In addition to waveform retracking, other sources of uncertainties arise from the 269 application of geophysical corrections to the altimetric sea surface height (SSH), 270 defined as the height measured with respect to an arbitrary reference level, called the 271 reference ellipsoid, which is not always optimised for the coastal domain. The main 
corrections used in this paper are listed in Table 2 and described in the following sections.

274 One of the most critical corrections is the wet tropospheric path delay, showing a 275 standard error of $+/-3 \mathrm{~cm}$ in the coastal domain (Smith et al., 2008). Approaching the 276 coast, wet tropospheric signals have a smaller space-temporal scale of variability, 277 which are poorly resolved by numerical models or are less precisely estimated by on278 board radiometer, the radiometric footprint being potentially corrupted by land 279 contaminations. Until recently, most altimeter data in a 10-30 km coastal band of the 280 NWMed were flagged as invalid and discarded from standard regional products 281 (Bouffard, 2007; Bouffard et al., 2008a, 2008b). The regional AVISO products used 282 in this study contain an enhanced wet tropospheric correction near the coast (more 283 details in Brown, 2010). The same approach has been applied to Jason-2 PEACHI 284 products (Valladeau et al., 2015). For SARAL PEACHI products, the method 285 described in Valladeau et al. (2015) has been applied, whereby the last valid 286 brightness temperature (BT) is extrapolated and considered in place of the 287 contaminated BT as input to the computation of the WTC - an approach that is less 288 accurate than the Brown (2010) method but much simpler to configure and 289 implement.

290 Although several algorithms for improving the wet path delay near the coast have 291 been developed recently (Cipollini et al., 2017; Desportes et al., 2010; Fernandes et 292 al., 2015; Fernandes and Lázaro, 2016), the detailed evaluation of related 293 improvements do not lie within the scope of the present paper, which mainly focuses 294 on the impact assessment of applying coastal-oriented retracking, editing and high295 resolution MDT. 
Both AVISO and PEACHI products use the Dry Tropospheric correction computed

297 from 6-hour span outputs from the ECMWF (European Centre for Medium-Range

298 Weather Forecasts) model. The dry tropospheric correction has a maximum standard

299 error of $+/-1-2 \mathrm{~cm}$ in the coastal domain (Smith et al., 2008).

300 For AVISO, the GOT4.8 (Ray, 2013) ocean tide solutions were applied, while the 301 FES2012 was used for PEACHI (Carrere et al., 2012), despite the tide signals (and 302 associated error) in the considered region being particularly low (Alberola et al., 303 1995).

304 With regard to the SSB, a 2D wind speed model as a function of backscatter and 305 Significant Wave Height (SWH) was developed in the framework of the PEACHI 306 project (Valladeau et al., 2015), while an empirical solution fitted on six months of 307 SARAL GDR_C data (from NOAA Laboratory for Satellite Altimetry) was used in 308 AVISO products (User Handbook Ssalto/DUACS, 2016). Alternative sea state bias 309 (SSB) solutions are available in literature (Tran et al., 2010; Pires et al., 2016), aimed 310 at developing a finer modelling of this effect, but have not been assessed in this 311 study. The accuracy of SSB is about $2 \mathrm{~cm}$ (Smith et al., 2008).

312 In addition to the previously mentioned correction, the Global Ionospheric Map 313 (GIM) from JPL (Jet Propulsion Laboratory) has been considered for the ionosphere 314 correction for both AVISO and PEACHI products. Although the most accurate way 315 to model the ionospheric effect is by using dual-frequency measurements (like in 316 Imel, 1994), this approach is not applicable to SARAL, as it is a monoband radar 317 altimeter. Thus, the JPL GIM model has been adopted in this study, as it is applicable 318 to both Jason-2 and SARAL. The ionospheric correction has an error budget of $+/-3$ $319 \mathrm{~cm}$ on derived SSH (Callahan, 1984). Both PEACHI and AVISO products are 
provided including a so-called Dynamic Atmospheric Correction (DAC) (Carrère and

321 Lyard, 2003).

\subsubsection{Coastal Editing Strategy}

324 As the PEACHI experimental products have a high rate sampling of $40 \mathrm{~Hz}$ for 325 SARAL and $20 \mathrm{~Hz}$ for Jason-2, specific editing and filtering procedures have been 326 developed, following methods described in Bouffard et al. (2010). Figure 2 depicts an 327 example of this procedure applied on AltiKa track \#429 in deriving the edited (red 328 curve) and filtered (green curve) heights from the raw data (blue curve).

329 First, a ten-step recurrent $2 *$ std editing algorithm was developed and applied to 330 corrected high-rate along-track PEACHI SLA in order to remove residual spikes (see 331 red curve on Figure 2). For each iteration, first, the difference between the altimetry 332 raw and smoothed data was computed and then spikes higher than two standard 333 deviations are flagged, removed and replaced by linearly interpolated values. The 334 next iteration begins from this result by performing the spikes filtering and smoothing 335 again. This recurrent procedure is repeated ten times in order to obtain the final edited 336 and filtered SLA. At the end of these editing steps, $4 \%$ of spikes were eliminated 337 from SARAL track \#429 and 12\% from SARAL track \#674, while 7\% spikes were 338 filtered out from Jason-2 track \#9. Thereafter, the edited high rate altimetric SLA was 339 low-pass filtered (using a moving average filter) with a window of $2.5 \mathrm{~km}$ for 340 SARAL (see green curve on Figure 2) and $8.5 \mathrm{~km}$ for Jason-2 in order to reduce 341 residual noise, as in Bouffard et al. (2010). The MVP derived currents and ADCP 342 currents were also smoothed from the raw signal with the same filter. Figure 2 also 343 shows (in black) the $1 \mathrm{~Hz}$ AVISO product, highlighting the differences with respect 344 to high-rate PEACHI products in terms of SLA-observed features. 


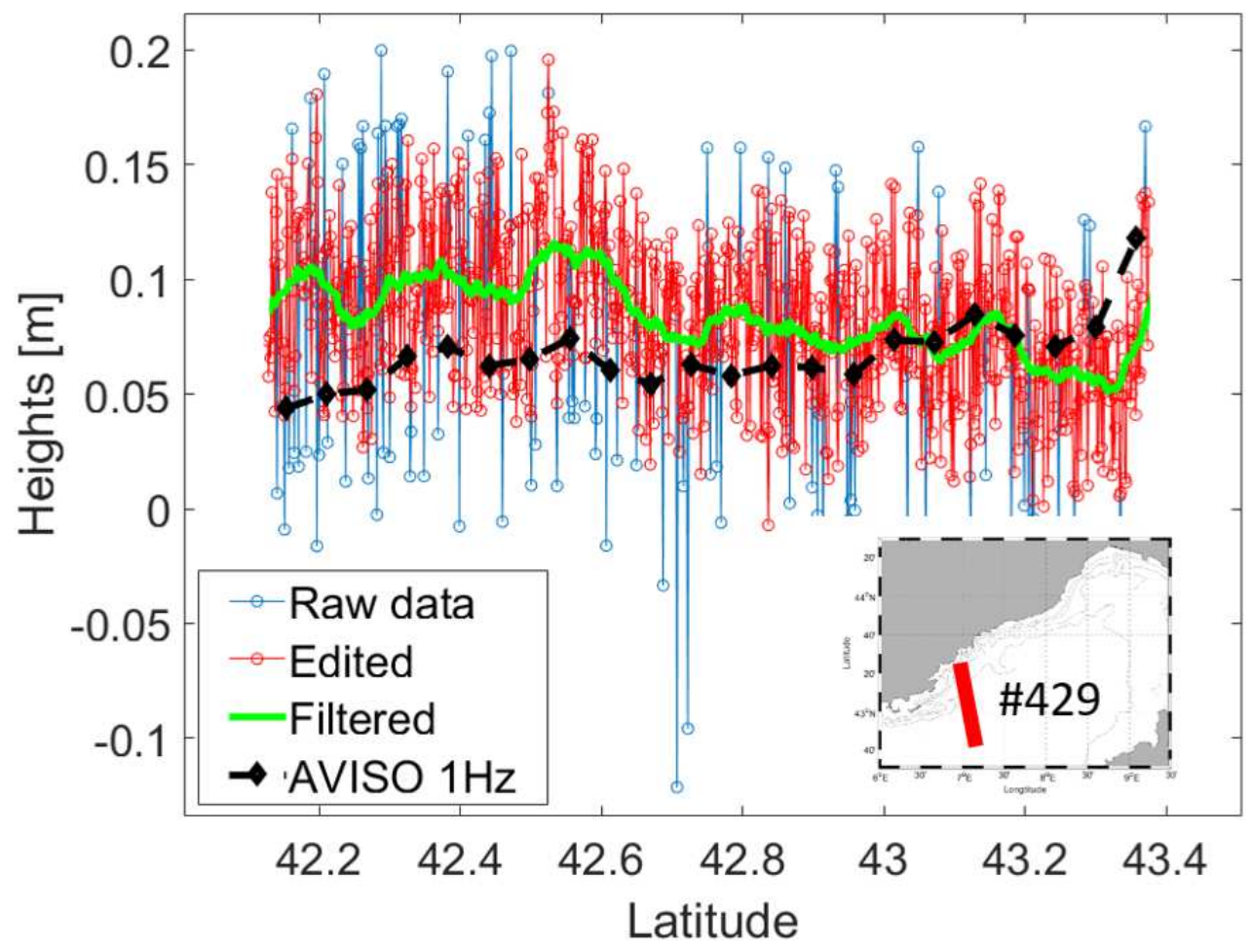

Figure 2 PEACHI high rate altimetry SLA editing and filtering for SARAL track \#429. The black line corresponds to the AVISO $1 \mathrm{~Hz}$ track.

\subsubsection{Mean Dynamic Topography (MDT)}

The AVISO and PEACHI absolute geostrophic currents were then calculated from

351 the ADT, using the Powell and Leben (2004) filtering with a cut-off distance of 15

$352 \mathrm{~km}$, roughly corresponding to the local Rossby radius of deformation over the study 353 area (Grilli and Pinardi, 1998). Two Mean Dynamic Topography (MDT) have been 354 considered, spatially interpolated and added to the altimetric SLA in order to obtain 355 the along-track ADT: the Rio "old” MDT (after RIO07), resolution 1/8 (Rio et al., 356 2007; see Figure 3a) and the Rio "new" MDT (RIO14) with resolution 1/16 (Rio et 357 al., 2014; see Figure 3b).

358 A linear interpolation was applied to both RIO07 and RIO14 gridded MDTs to obtain an along-track MDT to be added to the altimetry SLA measurements. 
360 The RIO14 benefits from the improvements enabled by the use of extended data sets

361 and refined processing techniques. The updated data set spans the 1993-2012 period

362 and consists of drifter velocities, altimetry data, hydrological profiles and model data.

363 The methodology is similar to the previous RIO07, which did not use any

364 hydrological profiles. As compared to the RIO07, the RIO14 therefore features

365 shorter-scale structures owing to the use of more in situ and satellite-based 366 observations. 

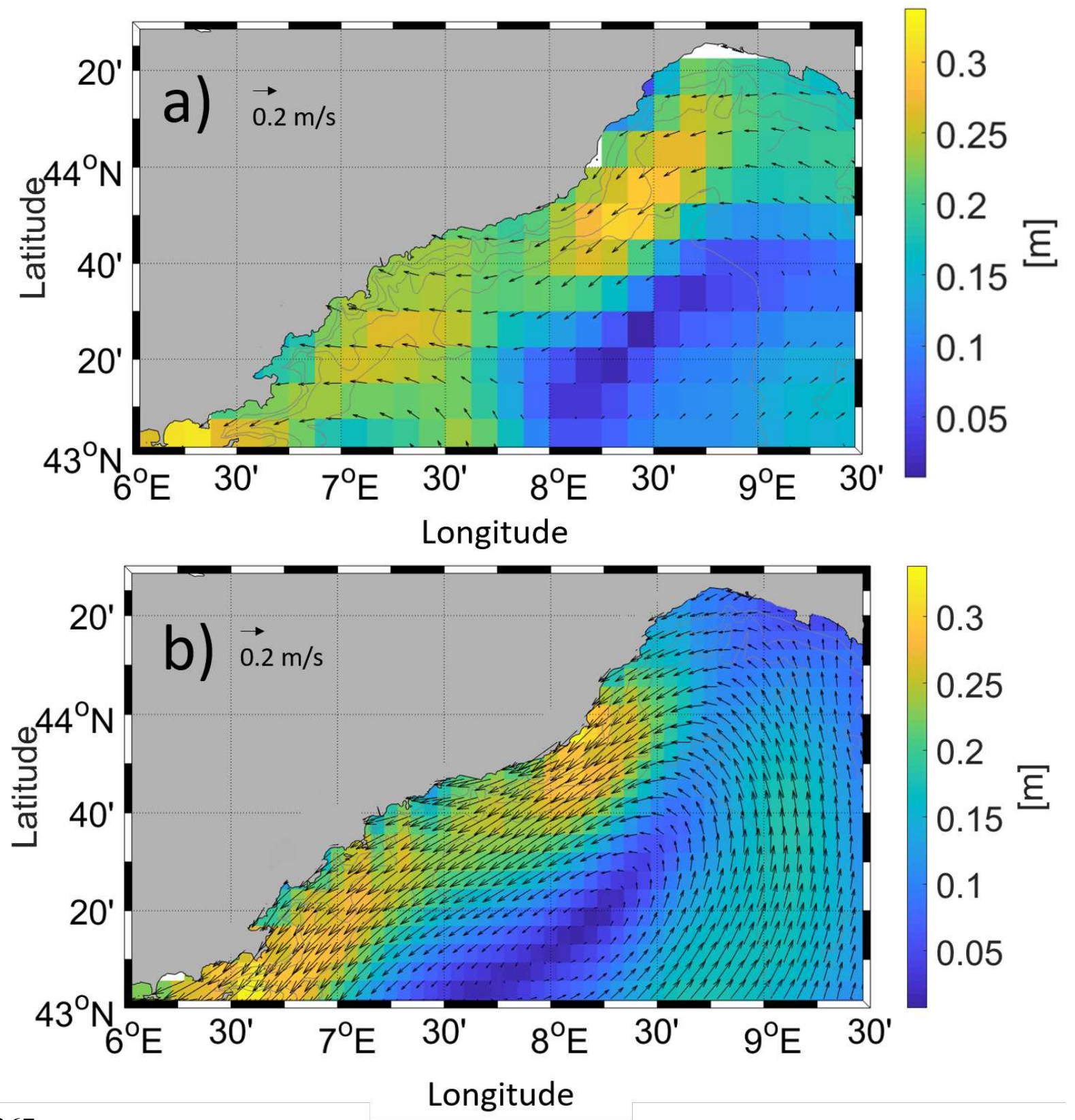


\begin{tabular}{|c|c|c|c|c|c|c|}
\hline SLA & MDT & Retracker & Sampling & SLA Coastal Editing & $\begin{array}{l}\text { Spatial } \\
\text { Filtering }\end{array}$ & Corrections \\
$\begin{array}{c}\text { AVISO } \\
\text { Jason-2 }\end{array}$ & $\begin{array}{l}\text { RIO14 } \\
\text { RIO07 }\end{array}$ & & & & Wet tropo (Brown, 2010) \\
Dry tropo (ECMWF Model) \\
AVISO \\
SARAL
\end{tabular}

371

3724 Results and discussions

\section{$373 \quad$ 4mpact of in situ MVP reference depth and sinopticity issue}

374 As reported in section 3.1, temperature, salinity and density fields retrieved by MVP

375 can be used to estimate DH with respect to an arbitrary reference depth, which is

376 supposed to be a no-motion level. As the reference depth issue does not affect

377 altimetry, a sensitivity study has been performed to highlight effects on the

378 computation of MVP-derived surface geostrophic current when compared to

379 altimetry (shown in Figure 4). The latter shows the different MVP-derived 
geostrophic currents computed by varying the reference depth, compared with

381 PEACHI geostrophic currents using the MLE4 retracker. Each of the four transects

382 has a different maximum depth for which valid measurements are available: $293 \mathrm{~m}$

383 for transect $A-B, 330 \mathrm{~m}$ for transect $\mathrm{D}-\mathrm{A}, 321 \mathrm{~m}$ for transect $\mathrm{G}-\mathrm{I}$ and $278 \mathrm{~m}$ for

384 transect $\mathrm{H}-\mathrm{G}$. Figure 5 reports the mean and standard deviation of the differences

385 between PEACHI and MVP at different reference depths.

386 Examining the comparison statistics reported in Figure 5, it can be seen that the

387 differences are reduced between altimetry and MVP datasets for transect D - A and H

$388-\mathrm{G}$ when considering a deeper reference level. For transect $\mathrm{H}-\mathrm{G}$, the difference

389 between the two sensors is reduced from $0.052 \mathrm{~m} / \mathrm{s}$ for a reference depth of $90 \mathrm{~m}$ to

$3900.028 \mathrm{~m} / \mathrm{s}$ for a reference depth of $278 \mathrm{~m}$. The same conclusion is obtained for

391 transect D - A and transect A - B with a mean reduction from $0.092 \mathrm{~m} / \mathrm{s}$ to $0.041 \mathrm{~m} / \mathrm{s}$

392 and from $0.210 \mathrm{~m} / \mathrm{s}$ to $0.178 \mathrm{~m} / \mathrm{s}$, respectively. This is potentially caused by the deep

393 flow of the NC along the Ligurian continental slope. The vertical temperature profile

394 shows the NC signature with a stronger temperature up to a depth of $90 \mathrm{~m}$ for

395 latitudes higher than $43.35^{\circ}$ (see Figure 10 and associated discussions).

396 The results obtained for the MVP transects out of the NC are different. For transect G

$397-\mathrm{I}$, the mean reduction of altimetry and MVP current difference is observed up to a

398 140-m depth, whereas the differences go up for a higher depth (as for surface layers).

399 This pattern could be potentially linked to the sub-surface currents associated with a

400 strong and rapidly evolving mesoscale feature intercepted by this transect but not 401 seen by transect $\mathrm{H}-\mathrm{G}$. Transects $\mathrm{G}-\mathrm{I}$ and $\mathrm{H}-\mathrm{G}$ are almost collocated but have a

402 time separation of about one day (see Table 2) during which dynamical conditions 403 may have changed with fine-scale surface features having moved in between the two 404 MVP passes. This is confirmed by examining the vertical temperature profiles on 
405 which changes are clearly observed along the water column (see Figure 10 and

406 associated discussions). These high-frequency variations cannot be observed by

407 instantaneous altimetry measurements, while they affect the MVP measurements all

408 along the data sampling, emphasising potential impacts of synoptic issues in

409 altimetric versus in situ comparisons.

410 According to the above results (also confirmed by using Red3 or Adaptive retrackers

411 in the sensitivity study) and despite the spotted sinopticity issue, the agreement

412 between altimetry and MVP is generally satisfying when considering the deepest

413 reference level (different for each of the four considered transect) as well as 20-30

$414 \mathrm{~km}$ offshore (the grey square on Figure 4). On one hand, the deepest reference level

415 has been kept for the remaining analyses and is the one adopted in the results

416 presented in section 4.3 On the other hand, two alternative retrackers (Red3,

417 Adaptive) have been used and evaluated to highlight the potential improvement in the

$418 \quad 20-30$ coastal bands. 

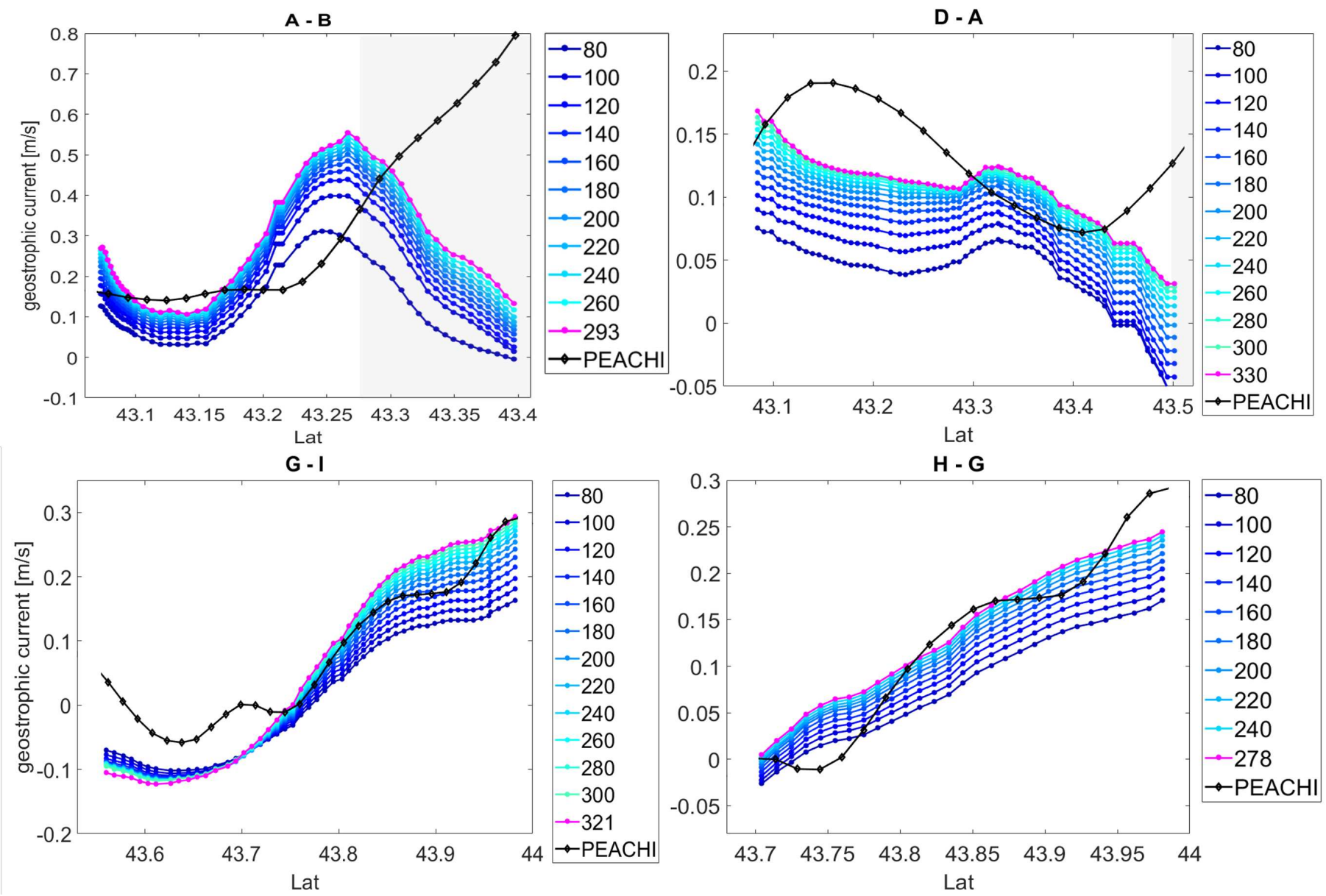

420 Figure 4 Reference depth sensitivity study for transects A - B, D - A, G - I and H - G. Different colours are

421 associated with different reference depths (in meters) considered in the vertical integration of MVP data

422 while the PEACHI altimetry data (MLE4 retracker) are shown in black. The magenta line represents the

423 MVP derived currents at the maximum operating depth. The shaded grey areas in transects A - B and D - 

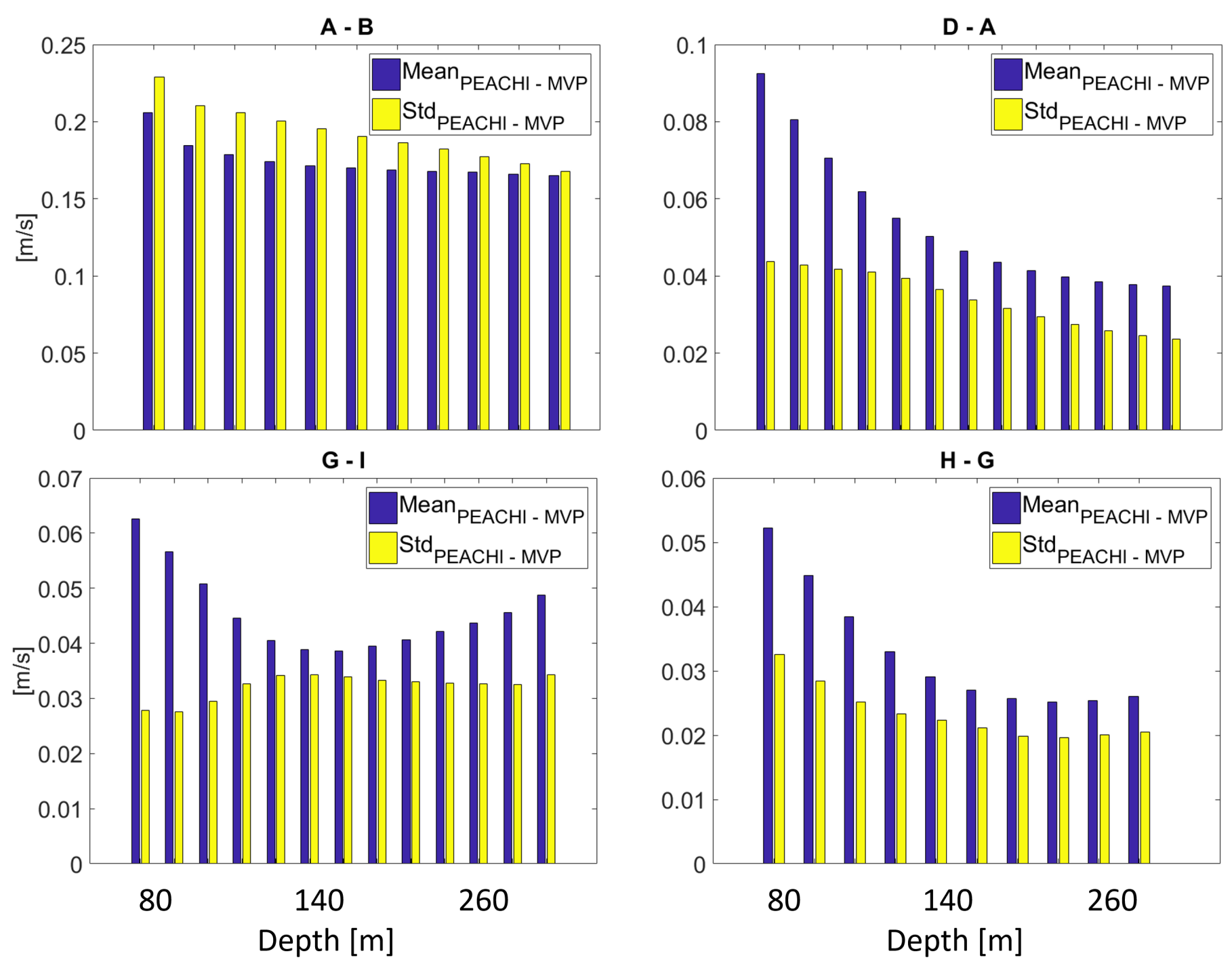

426

427 Figure 5 Mean (blue) and standard deviation (yellow) of the current differences between PEACHI and 428 MVP.

429 


\subsection{Impact of physical content and reference depth}

431 In order to assess the potential impact of the reference depth on the MVP retrieved

432 current, geographical plots of the differences of the surface across-track current

433 ADCP-MVP (coloured dots) have been computed (Figure 6), superposed to the cross-

434 track component of the deep ADCP current, measured at $270 \mathrm{~m}$ depth. Comparison

435 between surface across track MVP and ADCP derived currents are shown in Figure 7

436 for each of the cruise transects.

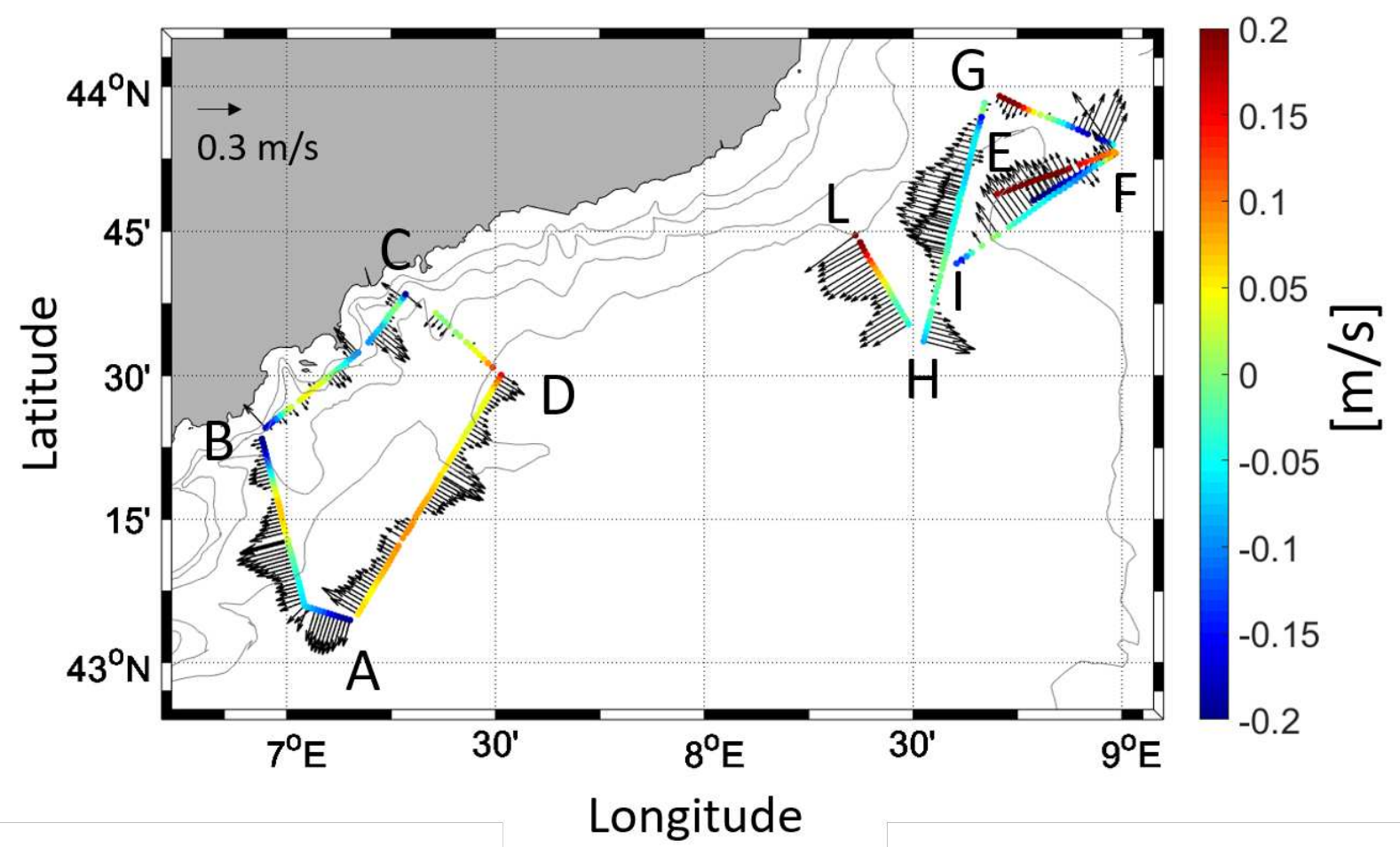

Figure 6 Geographical plot of the differences (coloured dots) of the surface across track current ADCP- 

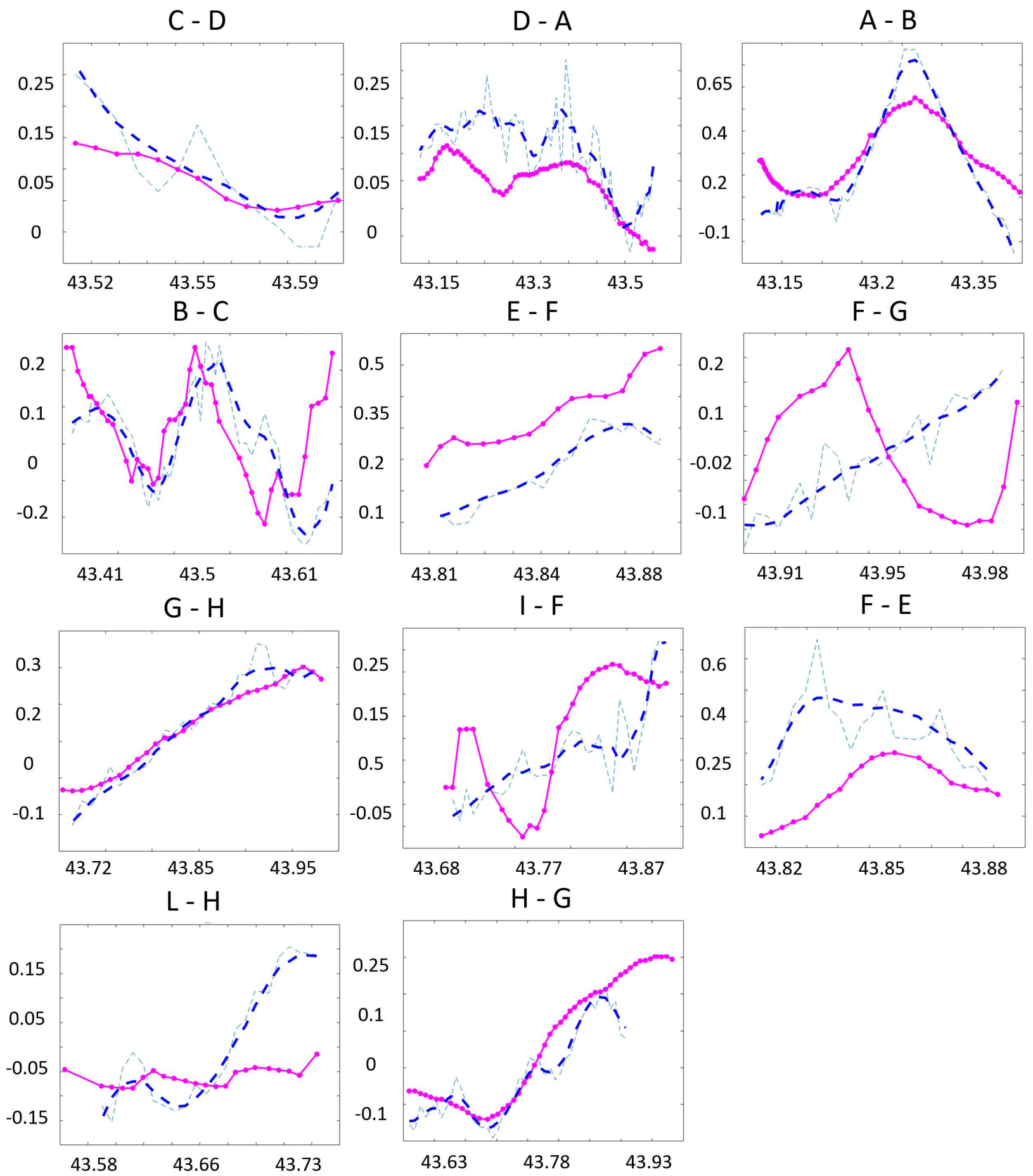

441 Figure 7 Comparison between MVP (magenta) and ADCP currents (m/s) vs. Latitude (raw data in thin blue, filtered and smoothed data in dashed thick blue) for each transect.

443 The principal differences between the two in situ observing systems highlighted in

444 Figure 7 should be mainly related to the fact that ADCP measures the total absolute 445 current and contains both geostrophic and ageostrophic motion, while the MVP 
measurements are referenced to an unknown no-motion level and - as altimetry -

447 capture the single geostrophic component.

448 Figure 6 shows that if a strong deep current is present at $270 \mathrm{~m}$, the no-motion 449 hypothesis is not verified, which consequently creates inconsistencies when 450 comparing DH-derived MVP currents with the ones from ADCP (and hence with 451 altimetry). This is evident from transect $F-G, E-F$ and $F-E$, where the differences 452 between the two observing systems are particularly high $\left(>0.16 \mathrm{~ms}^{-1}\right)$. This is also 453 valid when examining transect $\mathrm{A}-\mathrm{B}$, where a strong deep current is visible in Figure 4546 , generating a difference of $0.10 \mathrm{~ms}^{-1}$ between surface MVP and ADCP currents. On 455 the other hand, transects $\mathrm{G}-\mathrm{H}$ and $\mathrm{H}-\mathrm{G}$ show small differences and high 456 correlation $(>0.95)$, although the ADCP measurements show finer-scale dynamics, 457 perhaps due to ageostrophic variations that occurred during the time of route $\mathrm{H}-\mathrm{G}$ 458 and not during the same geographical transect $\mathrm{G}-\mathrm{H}$. During the period from October 45930 to November 2, 2015, a strong north-easterly wind event with velocity up to 70 $460 \mathrm{~km} \mathrm{~h}^{-1}$ was recorded over the whole area (Marrec et al., 2018), reinforcing high461 frequency and small-scale features

462 In addition, looking at in situ comparison statistics (Table 3), anticorrelated value was 463 found for transect $F-G$ as well as significant differences for transects $E-F, F-E$ 464 and F - G. Moreover, ADCP observations on Figure 7 show small-scale dynamics, 465 not depicted by altimetry and MVP (for example along the transect D - A), but 466 attesting the presence of high-frequency ageostrophic likely variations. 


\begin{tabular}{|c|c|c|c|c|c|c|c|}
\hline Transect & $\begin{array}{l}\text { Mean(ADCP- } \\
\text { MVP) [m] }\end{array}$ & $\begin{array}{l}\text { Std(ADCP- } \\
\text { MVP) }[\mathrm{m}]\end{array}$ & $\begin{array}{l}\text { Mean(M } \\
\text { VP) }[\mathrm{m}]\end{array}$ & $\begin{array}{l}\text { Std(MVP) } \\
{[\mathrm{m}]}\end{array}$ & $\begin{array}{l}\text { Mean(ADCP) } \\
{[\mathrm{m}]}\end{array}$ & $\begin{array}{l}\text { Std(ADCP) } \\
{[\mathrm{m}]}\end{array}$ & $\begin{array}{l}\text { Corr(ADCP, } \\
\text { MVP) }\end{array}$ \\
\hline C - D & 0.03 & 0.04 & 0.08 & 0.04 & 0.11 & 0.08 & 0.94 \\
\hline D - A & 0.06 & 0.03 & 0.10 & 0.05 & 0.16 & 0.06 & 0.81 \\
\hline A - B & 0.10 & 0.08 & 0.27 & 0.14 & 0.23 & 0.24 & 0.93 \\
\hline B - C & 0.13 & 0.13 & 0.03 & 0.10 & 0.00 & 0.13 & 0.44 \\
\hline E - F & 0.18 & 0.05 & 0.34 & 0.11 & 0.18 & 0.11 & 0.89 \\
\hline F- G & 0.18 & 0.07 & 0.01 & 0.12 & 0.00 & 0.10 & -0.59 \\
\hline G - H & 0.03 & 0.02 & 0.14 & 0.12 & 0.14 & 0.14 & 0.99 \\
\hline I- F & 0.12 & 0.06 & 0.12 & 0.14 & 0.07 & 0.10 & 0.51 \\
\hline F - E & 0.20 & 0.09 & 0.19 & 0.08 & 0.38 & 0.08 & 0.44 \\
\hline L - H & 0.08 & 0.08 & -0.06 & 0.02 & -0.01 & 0.12 & 0.72 \\
\hline H - G & 0.05 & 0.04 & 0.08 & 0.16 & -0.02 & 0.12 & 0.95 \\
\hline
\end{tabular}

471

472 After geostrophy, one of the major contributions to the ocean surface currents is the

473 Ekman response of the ocean to high-frequency wind stress. Various studies have

474 focused on understanding and modelling these currents in a more effective and

475 comprehensive manner (Ralph and Niiler, 1999; Lagerloef et al., 1999; Elipot and

476 Gille, 2009; Rio et al., 2003, 2011, 2012). The potential impacts of ageostrophy

477 signatures from Ekman have been tentatively assessed in this study using

478 GlobCurrent version 2 Ekman current at $0.25^{\circ}$ resolution, 3-hourly, available from

4792002 to 2014 (accessed from http://www.globcurrent.org/). However, due to the

480 coarse resolution of the GlobCurrent products and a lack of coverage over the coastal

481 domain, it was not possible to assess precise Ekman impacts on the study area. A

482 product with finer resolution should be processed in future GlobCurrent versions but

483 was not available at the time of this study.

484 The following section reports the comparison between satellite altimetry and MVP

485 with particular emphasis on the impacts of altimetry processing. 
489 SARAL tracks \#429 and \#674 together with Jason-2 track \#9 SLA, ADT and derived 490 currents were compared to MVP geo-located measurements (Figure 8). Tables 4 and 4915 report the mean statistical scores per mission. In total, combinations of 12 492 comparisons per track have been performed between satellite altimetry measurements 493 (considering different products, MDT and corrections) and in situ MVP/ADCP 494 transects. The analysis has been performed up to $14.5 \mathrm{~km}$ from the coast for SARAL 495 track \#429, $37 \mathrm{~km}$ for SARAL track \#674 and up to $13 \mathrm{~km}$ for Jason-2 track \#9.

496 Examining the comparison plots between Jason-2 track \#9 and MVP transect A-D 497 (Figure 8a), it can be seen that the two bumps visible in currents at Latitude $43.2^{\circ}$ and $49843.4^{\circ}$ are related to the interception of the $\mathrm{NC}$, which intersects the altimetric track 499 twice due to its orientation with respect to the main flow. The NC signature is also 500 evident when looking at SARAL track \#429 from which the main current peak of $5010.55 \mathrm{~m} / \mathrm{s}$ at Latitude $43.25^{\circ}$ is captured by MVP and ADCP measurements (Figure 502 8b). Along the SARAL track \#674 and in situ transects G - I and H - G, a dipole-like 503 mesoscale structure is observed in each altimetric dataset (see section 4.4; Figures 8c 504 and $8 d)$.

505 Despite good general agreement between altimetry and MVP, some important 506 discrepancies were also observed. For track \#429, the mean difference with respect to 507 the MVP and ADCP current are $0.08 \mathrm{~m} / \mathrm{s}$ and $0.20 \mathrm{~m} / \mathrm{s}$, respectively. These 508 significant differences might potentially be due to land contamination affecting 509 altimetry measurements approaching the coast and not processed with optimal 510 retracking and/or local corrections. MVP and ADCP show some disagreements along 511 the transect $\mathrm{A}-\mathrm{D}$, whereas ADCP - not affected by reference level issue - and 
512 altimetry (track \#9) show quite a similar pattern with an increasing velocity when 513 approaching the coastline.

514 When compared to ADCP and MVP-derived current, the benefit of adding MDT to 515 the altimetric SLA is obviously confirmed for all considered tracks and missions; this 516 is particularly evident for SARAL tracks, for which an improvement of $30 \%$ in 517 correlation was observed. When compared to the RIO07 MDT, the use of the RIO14 518 further improves the comparison scores in terms of correlation between altimetry data 519 and MVP, with a mean increase of $10 \%$ for both AVISO and PEACHI products 520 (Tables 4 and 5).

521 Using the PEACHI products, the mean and standard deviation differences between 522 MVP and altimetry are still reduced: the overall mean difference goes from $0.04 \mathrm{~m} / \mathrm{s}$ 523 to $0.02 \mathrm{~m} / \mathrm{s}$ for SARAL and from $0.35 \mathrm{~m} / \mathrm{s}$ to $0.26 \mathrm{~m} / \mathrm{s}$ for Jason-2 for $1 \mathrm{~Hz}$ AVISO 524 and PEACHI products respectively. Comparison statistics (Table 4) show that for 525 PEACHI products, the adaptive retracker provides better performances in coastal 526 regions (correlation > 0.9) for both $40 \mathrm{~Hz}$ SARAL and $20 \mathrm{~Hz}$ Jason-2 sensors when 527 compared to standard $1 \mathrm{~Hz}$ regional AVISO.

528 With regard to previous studies (Birol et al., 2015; Verron et al., 2015; Troupin et al., 529 2015), considering AltiKa sensor on-board, SARAL provides better statistical 530 agreement with in situ than the Ku-band mission, such as Jason-2 and, particularly in 531 this study, using the combination with RIO14 and adaptive retracking, confirming 532 that the Ka band is more reliable in resolving fine-scale coastal dynamics. 

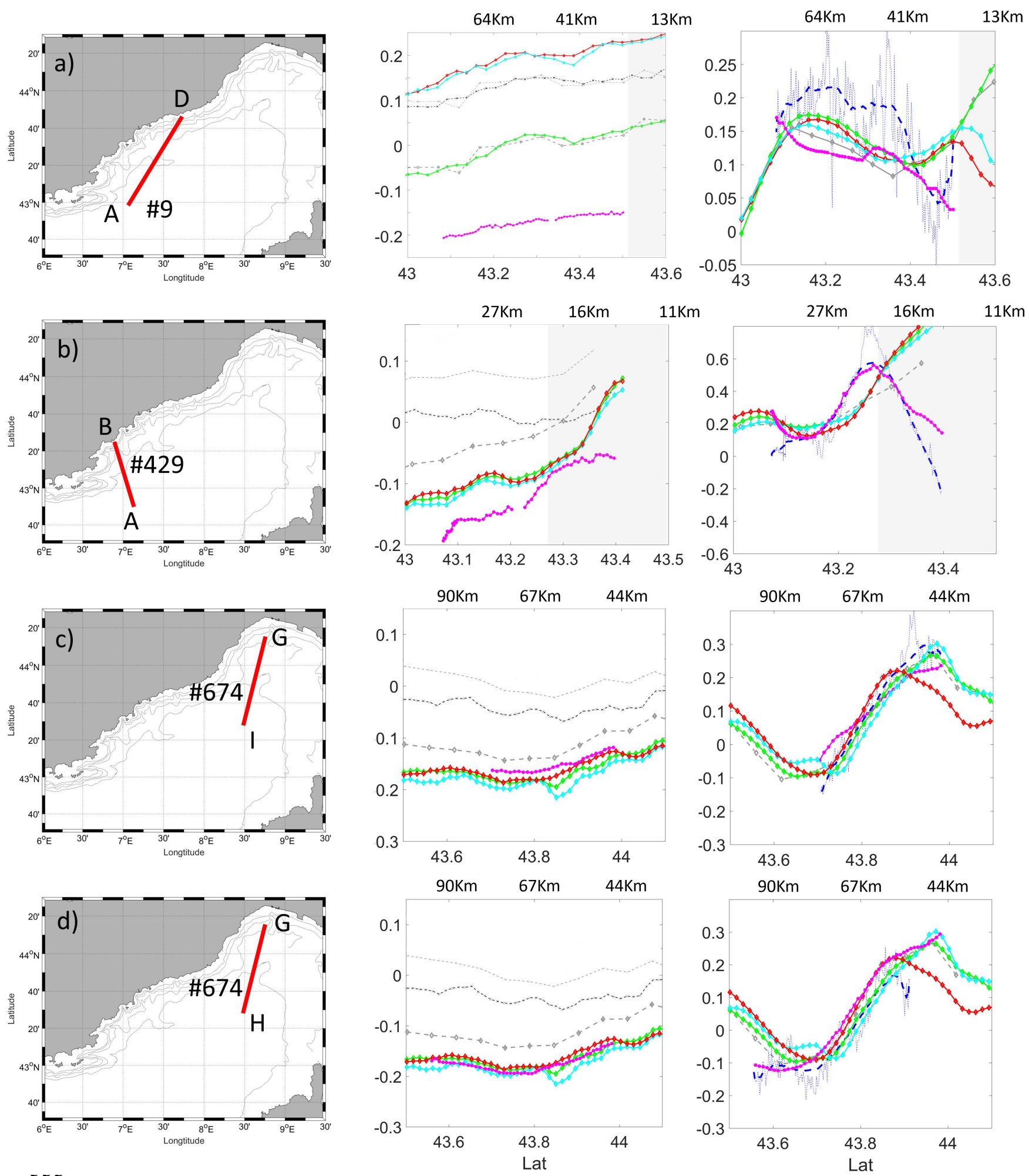

534 Figure 8 PEACHI Altimetry (grey for SLA+RIO07 and red for adaptive retracking, cyan for Red3 retracking

535 and green for MLE4 retracking for SLA+RIO14) vs AVISO altimetry (light grey for SLA+RIO07 and grey for

536 SLA+RIO14) vs in situ (magenta for MVP, blue for ADCP). The different markers used for both AVISO and

PEACHI altimetry are related to elevations and currents computed with a different MDT (crosses for RIO07 
and diamonds for RIO14). First column reports track geolocation, second column reports ADTs (m) vs Latitude

and third column reports satellite across track current (ms-1) derived from ADT computed only adding RIO14

to SLA vs Latitude together with in situ derived current vs Latitude. The distance to the coast is also reported in

kilometres.

542

543

544

Table 4 PEACHI ADT and V vs MVP average comparison statistics (correlation) per retracking method (the level of significance is $95 \%$ )

545

\begin{tabular}{|c|c|c|c|c|c|c|}
\hline Satellite & MDT & Parameter & Adaptive & MLE4 & RED3 & $\begin{array}{l}\text { Total Average } \\
\text { per MDT }\end{array}$ \\
\hline \multirow{6}{*}{ SARAL } & \multirow{2}{*}{ RIO14 } & ADT & 0.93 & 0.90 & 0.78 & 0.87 \\
\hline & & V & 0.75 & 0.67 & 0.79 & 0.74 \\
\hline & \multirow{2}{*}{ RIO07 } & ADT & 0.58 & 0.55 & 0.30 & 0.48 \\
\hline & & V & 0.76 & 0.51 & 0.71 & 0.66 \\
\hline & \multirow{2}{*}{$\begin{array}{l}\text { Total Average } \\
\text { per Retracking }\end{array}$} & ADT & 0.75 & 0.72 & 0.54 & 0.67 \\
\hline & & V & 0.76 & 0.59 & 0.75 & 0.70 \\
\hline \multirow{6}{*}{ Jason-2 } & \multirow{2}{*}{ RIO14 } & ADT & 0.92 & 0.91 & 0.77 & 0.87 \\
\hline & & $\mathrm{V}$ & 0.71 & 0.74 & 0.73 & 0.73 \\
\hline & \multirow{2}{*}{$\mathrm{RIO07}$} & ADT & 0.83 & 0.81 & 0.71 & 0.79 \\
\hline & & V & 0.70 & 0.74 & 0.72 & 0.72 \\
\hline & \multirow{2}{*}{$\begin{array}{l}\text { Total Average } \\
\text { per Retracking }\end{array}$} & ADT & 0.88 & 0.86 & 0.74 & 0.83 \\
\hline & & $\mathrm{V}$ & 0.71 & 0.74 & 0.73 & 0.72 \\
\hline
\end{tabular}

546

547

548

Table 5 AVISO ADT and V vs MVP average comparison statistics (correlation) per retracking method (the level of significance is $95 \%$ )

\begin{tabular}{|c|c|c|c|}
\hline Satellite & MDT & Parameter & MLE3 \\
\hline \multirow{6}{*}{ SARAL } & \multirow{2}{*}{ RIO14 } & ADT & 0.86 \\
\hline & & $\mathrm{V}$ & 0.82 \\
\hline & \multirow{2}{*}{ RIO07 } & ADT & 0.60 \\
\hline & & $\mathrm{V}$ & 0.76 \\
\hline & \multirow{2}{*}{$\begin{array}{l}\text { Total Average } \\
\text { per Retracking }\end{array}$} & ADT & 0.73 \\
\hline & & V & 0.79 \\
\hline \multirow{6}{*}{ Jason-2 } & \multirow{2}{*}{ RIO14 } & ADT & 0.87 \\
\hline & & $\mathrm{V}$ & 0.71 \\
\hline & \multirow{2}{*}{ RIO07 } & ADT & 0.70 \\
\hline & & $\mathrm{V}$ & 0.68 \\
\hline & \multirow{2}{*}{$\begin{array}{l}\text { Total Average } \\
\text { per Retracking }\end{array}$} & ADT & 0.79 \\
\hline & & $\mathrm{V}$ & 0.70 \\
\hline
\end{tabular}


551 From a general point of view, the comparison between altimetry and MVP over the

552 study area is improved when considering experimental PEACHI high-rate altimetry 553 data rather than the Mediterranean regional AVISO products. The NC signatures and 554 small-scale oceanic features are, however, well captured by both datasets. Despite 555 this encouraging result and as testified by cross-comparisons with collocated ADCP 556 transects, the MVP measurements cannot be considered as a perfect reference dataset 557 for validating coastal altimetry. This is due to its sensitivity to the reference level 558 with regard to determining the DH along with the highlighted sinopticity issues 559 induced by high frequency and partially ageostrophic small-scale dynamics occurring 560 during data acquisition.

\subsection{Observed circulation patterns}

563 As shown on Figure 9, the combined use of surface altimetry and sub-surface in situ

564 measurements (MVP and ADCP) allows the observation of small scale and coastal

565 hydrodynamic features that are consistent with frontal structures depicted by 566 PODAAC Sea Surface Temperature data (SST, L4 data, JPL OurOcean Project, 567 2010).

568 In Figure 9, looking at transect $\mathrm{A}-\mathrm{B}$, the $\mathrm{NC}$ main path, with high current velocity

$569\left(>0.3 \mathrm{~ms}^{-1}\right)$ is intercepted by altimetry around Latitude $43.25^{\circ}$ and $6.8^{\circ}$ Longitude.

570 The associated surface frontal structure is also clearly captured by ADCP and MVP571 derived current as well as from remote-sensing SST image. There, the vertical 572 structure is characterised by the temperature profile of MVP, with higher temperature $573>18{ }^{\circ} \mathrm{C}$ (Figure 10) caused by the NC main flow and depicted up to its maximum 574 depth $(80 \mathrm{~m})$. 
575 More East and offshore, an eddy-like structure is instead depicted at the surface by 576 altimetry, ADCP and MVP-derived currents along the transect $\mathrm{G}-\mathrm{I}$. Along the same 577 transect, satellite SST also shows a zone of low temperature with values below $17{ }^{\circ} \mathrm{C}$. 578 This zone is surrounded by warmer boundary waters characterised by SST higher 579 than $17^{\circ} \mathrm{C}$, suggesting ascendant vertical pumping of cold water in the central part of 580 this small-scale dynamical feature.

581 Both in situ and satellite-derived surface current directions indicate that this 582 mesoscale feature is linked to a cyclonic recirculation of the NC in the Ligurian sub583 basin. Marrec et al. (2018) reported on this event, also attributing the important role 584 of Ekman pumping, induced by a strong wind event just before the OSCAHR cruise, 585 which has an impact on ocean biogeochemistry. Besides the strong wind event 586 occurring during the first day of the cruise, the region has experienced several wind 587 events two weeks before the cruise (Marrec et al., 2018), inducing a strong decline in 588 SST. The low temperature patch described by satellite SST and MVP profile supports 589 the Ekman pumping hypothesis. This process was also important in fertilizing the 590 upper layer with nutrient-rich upwelled waters.

591 Figure 10 depicts the salinity and temperature vertical sections of MVP transects A $592 \mathrm{~B}, \mathrm{G}-\mathrm{I}, \mathrm{H}-\mathrm{G}$ and $\mathrm{D}-\mathrm{A}$. In transect $\mathrm{G}-\mathrm{I}$, the sea surface salinity (SSS) was lower $593(<38.20)$ in the cold core than in the warm boundaries $(>38.20)$ and salinity at $300 \mathrm{~m}$ 594 in depth was higher than 38.50. A subsurface layer of low-salinity waters $(<38.10)$ is 595 present with a 40 to $80 \mathrm{~m}$ thickness. This subsurface layer was observed up to the 596 surface in the centre of the cold core (between Latitude $43.7^{\circ}$ and Latitude $43.8^{\circ}$ ), 597 whereas in warm boundaries, saltier (> 35.20) surface waters overlaid it. Low-salinity 598 waters $(<38.10)$ at the surface of the cold patch support the vertical Ekman pumping 599 hypothesis, as suggested from multi-sensor surface observations reported in Figure 9. 
600 Transect $\mathrm{H}-\mathrm{G}$ presents a lower salinity band $(<38.10)$ between $40 \mathrm{~m}$ to $80 \mathrm{~m}$ but

601 without reaching the surface, as for transect $G-I$. Higher values of depth salinity are

602 confirmed also for this transect. On transect $\mathrm{A}-\mathrm{B}$, where the signature of the $\mathrm{NC}$ is

603 clearly visible from the temperature profile (Figure 10) and altimetric-derived current

604 (Figure 9), the salinity values present lower values between 40 and $50 \mathrm{~m}$ depth in the

605 Latitude range between $43.1^{\circ}$ and $43.2^{\circ}$ to reach a thickness of $100 \mathrm{~m}$ (i.e. from $50 \mathrm{~m}$

606 to $150 \mathrm{~m}$ ) from Latitude $43.3^{\circ}$ and Latitude $43.5^{\circ}$. The same features are observed in

607 transect D - A, but the lower values of salinity reach a depth of $100 \mathrm{~m}$.

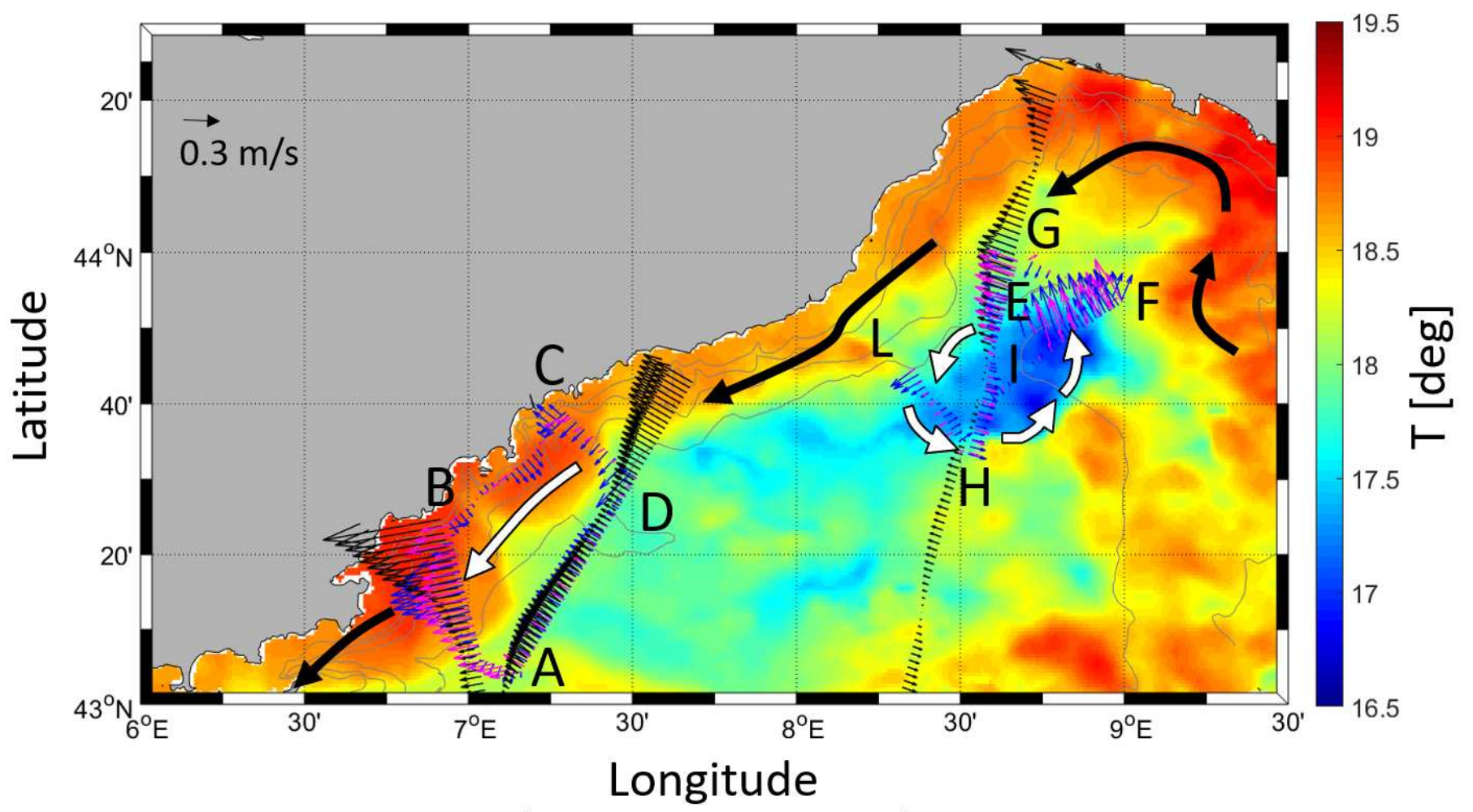

608

609 Figure 9 Surface circulation pattern derived from in situ (magenta for MVP and blue for ADCP) and

610 PEACHI altimetry data (black). SST data is also shown with a Spatial Resolution of $0.062^{\circ}$ (Latitude) $x$

$6110.062^{\circ}$ (Longitude) and temporal resolution of 1 day. The SST maps is an average over the OSCAHR cruise

612 time period October 29, 2015 to November 06, 2015). White arrows depict the surface oceanographic

613

features reported also in Figure 10 vertical profiles.

614 

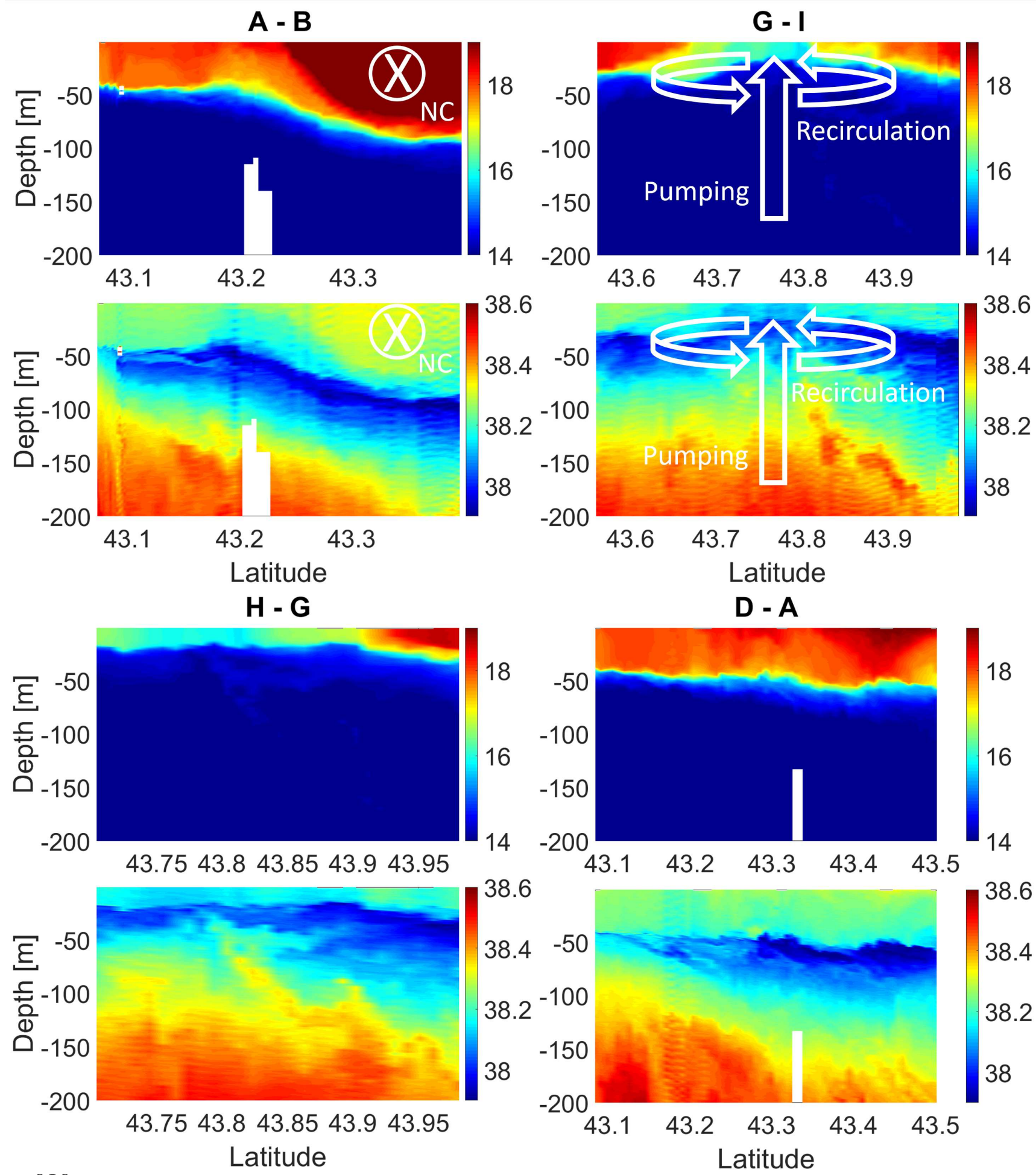

617 Figure 10 MVP Salinity and temperature vertical profiles. The oceanographic features have been depicted 618 with white arrows.

619 
621 The monitoring of small-scale processes in the coastal domain using satellite-based 622 observations represents a key challenge in oceanography. In this paper, we discussed 623 the issue of validating and optimising coastal altimetry data in areas characterised by 624 fine-scale dynamics.

625 It has been discussed that regional $1 \mathrm{~Hz}$ altimetric data from AVISO are not always 626 reliable close to the coast, and new experimental post processed and edited high rate 627 PEACHI altimetric data have been considered to better resolve regional fine-scale 628 features. Comparison statistics show that experimental high-rate PEACHI products 629 using the adaptive retracker provide better performances in coastal regions for both $63040 \mathrm{~Hz}$ SARAL and $20 \mathrm{~Hz}$ Jason-2 missions. Moreover, the use of the new RIO14 631 MDT instead of the RIO07 one increases the correlation scores with respect to in situ 632 measurements.

633 The use of MVP platform has been assessed, as it was never used for validating 634 coastal altimetry, highlighting the main challenges, advantages and limitations with 635 respect to gliders. Further, regarding the MVP dataset, the importance of the 636 reference level and sinopticity issues were discussed, and a sensitivity study was 637 performed to highlight the effect on the derived geostrophic currents. It has been 638 shown that, as for glider, measurements from the MVP are very promising for 639 validating coastal altimetry techniques but cannot be considered as a perfect reference 640 dataset by themselves. In this respect, the combined use of collocated MVP, altimetry 641 and ADCP appears to be relevant, not only for validation purpose but also to better 642 characterise the surface and sub-surface regional dynamics of the study area, 643 including the North Current flow and the induced cyclonic recirculation in the eastern 644 side of the Ligurian Sea. New benchmarking will also be performed, where the most 
645 recent developments in geophysical corrections and new retracking methods in 646 coastal domains will be taken into consideration.

647 From a more general point of view, this study illustrated the complexity of setting up 648 adequate in situ validation networks for coastal altimetry in areas dominated by 649 geostrophic and ageostrophic fine-scale oceanographic processes. It confirmed the 650 key importance of developing ad-hoc validation approaches using multiple types of 651 collocated instruments, which allow diagnosing and understanding the physical 652 content and mechanisms of the observed oceanic features. Recent (Sentinel-3) and 653 future high-resolution topographic missions, such as Jason-CS, Sentinel-6 and 654 SWOT, will continue to provide improved ocean parameters that can significantly 655 help in understanding climate changes, coastal and (sub-)mesoscale dynamics. Their 656 full exploitation and integration into re-analysis and forecasting system will however 657 depend on our capability to continuously develop science-oriented diagnostics and 658 uncertainty estimation. This objective can only be achieved through the deployment 659 and maintenance of long-term, independent, fully characterised and traceable multi660 sensor in situ observations (so-called "Fiducial Reference Measurements", FRM), 661 collocated along altimetry tracks.

662

\section{Acknowledgments}

664 We would like to thank the DT-INSU people from la Seyne sur Mer and, in 665 particular, Malika Oudia for her help in the administration work and Céline 666 Heyndrickx and Frédéric Le Moal for their technical support. We would specially

667 like to mention Genavir and Julien Fenouil for assisting us with the MVP.

668 MVP and the associated captors were brought by IFREMER and LOPB with co669 funding by the Centre Européen de Technologies Sous-Marine (CETSM - Contrat de 
670 Projet Etat Région 2007-2013 en PACA) and the French ANR FOCEA (project 671 ANR-09-CEXC- 006-01 to M. Zhou and F. Carlotti). We would also like to extend 672 our thanks to J. Thomas Farrar (MIT) for his suggestions on the cruise strategy. The 673 OSCAHR cruise was supported by the MIO Axes Transverses" programme (AT674 COUPLAGE), CHROME (PI M. Thyssen, funded by the Excellence Initiative of 675 Aix-Marseille University - A*MIDEX, a French "Investissements d'Avenir" 676 program), SeaQUEST (PI O. Ross, funded by the UE FP7 people), AMICO (PI C.

677 Pinazo, funded by Copernicus - MEDDE French Ministery MDE), and BIOSWOT 678 (PI F. d'Ovidio, funded by TOSCA/CNES). We also thank the captain and crew of 679 the Téthys II research vessel. The project leading to this publication received funding 680 from the European FEDER Fund under project 1166-39417. We are grateful for the 681 support of Labex OT-Med (no. ANR-11-LABX-0061), funded by the French 682 government through the A*MIDEX project (no. ANR-11-IDEX-0001-02).

683 The altimeter products were produced by Ssalto/Duacs and distributed by Aviso, with 684 support from Cnes (http://www.aviso.altimetry.fr/duacs/)".

685 The Group for High Resolution Sea Surface Temperature (GHRSST) Multi-scale 686 Ultra-high Resolution (MUR) SST data were obtained from the NASA EOSDIS 687 Physical Oceanography Distributed Active Archive Center (PO.DAAC) at the Jet 688 Propulsion Laboratory, Pasadena, CA (http://dx.doi.org/10.5067/GHGMR-4FJ01). 689 
691 Alberola, C., Rousseau, S., Millot, C., Astraldi, M., Garcia- Lafuente, J.J., Gasparini, 692 G.P., Send, U., Vangriesheim, A., 1995. Tidal currents in the Western 693 Mediterranean Sea. Oceanol. Acta. 18(2), 273-284.

694 Aulicino, G., Cotroneo, Y., Ruiz, S., Sánchez Román, A., Pascual, A., Fusco, G. 695 Budillon, G. 2018. Monitoring the Algerian Basin through glider observations, 696 satellite altimetry and numerical simulations along a SARAL/AltiKa track. J. 697 Mar. Syst. 179, 55-71. https://doi.org/10.1016/j.jmarsys.2017.11.006.

698 Amarouche, L., P. Thibaut, O.-Z. Zanife, J. P. Dumont, P. Vincent, N. Steunou, 2004. 699 Improving the Jason-1 ground tracking to better account for attitude effects. Mar $700 \quad$ Geod. 27(1-2), 171-197.

701 Anzenhofer, M., Shum, C.K., Rentsh, M., 1999. Coastal altimetry and applications, 702 Tech. Rep. 464, Geodedic Science and Survey, Ohio State University, Columbus.

703 Barrier, N., Petrenko, A., Ourmieres, Y., 2016. Strong intrusions of the Northern 704 Mediterranean Current on the eastern Gulf of Lion: Insights from in-situ observations and high resolution numerical modelling. Ocean Dynamics, Springer Verlag. 66(3), 313-327.

707 Birol, F., Delebecque, C., 2014. Using high sampling rate $(10 / 20 \mathrm{~Hz})$ altimeter data 708 for the observation of coastal surface currents: A case study over the 709 Northwestern Mediterranean Sea. J. Mar. Syst. 129, 318-333, 710 doi:10.1016/j.jmarsys.2013.07.009.

711 Birol, F., Niño, F., 2015. Ku and Ka-Band Altimeter Data in the Northwestern 712 Mediterranean Sea. Mar. Geod. 38, 313-327, doi:10.1080/01490419.2015.1034814. 
Birol, F., Cancet, M., Estournel, C., 2010. Aspects of the seasonal variability of the Northern Current (NW Mediterranean Sea) observed by altimetry. J. Mar. Syst. 81, 297-311. doi: 10.1016/j.jmarsys.2010.01.005.

Bonnefond, P., Laurain, O., Exertier, P., Boy, F., Guinle, T., Picot, N., Labroue, S., Raynal, M., Donlon, C., Féménias, P., Parrinello, T., Dinardo, S., 2018. Calibrating the SAR SSH of Sentinel-3A and CryoSat-2 over the Corsica Facilities. Remote Sensing. 10, 92.

Bouffard, J., S. Vignudelli, P. Cipollini, Menard, Y., 2008a. Exploiting the potential of an improved multimission altimetric data set over the coastal ocean. Geophys. Res. Lett. 35, L10601. doi: 10.1029/2008GL033488.

Bouffard, J., Vignudelli, S., Herrmann, M., Lyard, F., Marsaleix, P., Menard, Y., Cipollini, P., 2008b. Comparison of ocean dynamics with a regional circulation model and improved altimetry in the North-Western Mediterranean. Terrestrial Atmos. Oceanic Sci. 19.

Bouffard, J., F. Nencioli, R. Escudier, A. M. Doglioli, A. A. Petrenko, A. Pascual, P.M. Poulain, Elhmaidi, D., 2014. Lagangian analysis of satellite-derived currents: Application to the North Western Mediterranean coastal dynamics. Adv. Space Res. 53, 788-801.

Bouffard, J., Naeije, M., Banks, C. J., Calafat, F. M., Cipollini, P., Snaith, H. M., Webb, E., Hall, A., Mannan, R., Féménias, P., Parrinello T., 2017. CryoSat ocean product quality status and future evolution. Adv. Space Res. https://doi.org/10.1016/j.asr.2017.11.043.

Bouffard, J., Roblou, L., Birol, F., Pascual, A., Fenoglio-Marc, L., Cancet, M., Morrow, R., Me'nard, Y., 2011. Introduction and assessment of improved coastal 
altimetry strategies: case study over the North Western Mediterranean Sea, in: Altimetry. Springer, Berlin, Heidelberg, pp. 297-330.

Bouffard, J., Pascual, A., Ruiz, S., Faugère, Y., Tintoré, J., 2010. Coastal and mesoscale dynamics characterization using altimetry and gliders: A case study in the Balearic Sea. J. Geophys. Res. 115, C10029. https://doi.org/10.1029/2009JC006087.

Bouffard, J., Renault, L., Ruiz, S., Pascual, A., Dufau, C., Tintoré, J., 2012. Subsurface small-scale eddy dynamics from multi-sensor observations and modelling. Prog. Oceanogr. 106, 62-79. ISSN 0079-6611. doi: 10.1016/j.pocean.2012.06.007.

Brooks, R.L, Lockwood, D.W., Lee, J.E., Hancock, D.W.I., Hayne, G.S., 1998. Land effects on Topex radar altimeter measurements in pacific rim coastal zones, in: Brown, R.A. (Ed.), Remote Sensing of the Pacific Ocean by Satellites. Earth Ocean \& Space Pty. Ltd., Eveleigh, NSW, pp. 175-198.

Brown, G.S., 1997. The average impulse response of a rough surface and its applications. IEEE Trans. Antennas Propagation, AP-25. 67-74.

Brown, S., 2010. A novel near-land radiometer wet path-delay retrieval algorithm: Application to the Jason-2/OSTM advanced microwave radiometer. IEEE Trans Geosci. Remote Sens. 48(4), 1986.

Calafat, F.M., Cipollini, P., Bouffard, J., Snaith, H., Féménias, P., 2016. First evaluation of new CryoSat-2 products over the ocean. Remote Sens. Environ. 191, 131-144. doi: 10.1016/j.rse.2017.01.009. 
761 Callahan, P. S., 1984. Ionospheric variations affecting altimeter measurements: A brief synopsis. Mar. Geod. 8, 249-263.

763 Carrère L., Lyard, F., 2003. Modeling the barotropic response of the global ocean to atmospheric wind and pressure forcing - comparisons with observations. Geophys. Res. Lett. 30(6), 1275. doi:10.1029/2002GL016473.

Carrere, L., Lyard, F., Cancet, M., Guillot, A., Roblou, L., 2012. FES 2012: A new global tidal model taking advantage of nearly 20 years of altimetry. Proc. 20 Years Altimetry, Venice, Italy.

Cipollini, P., Benveniste, J., Bouffard, J., Emery, W., Fenoglio-Marc, L., Gommenginger, C., Griffin, D.A., Hoyer, J., Kurapov, A., Madsen, K., Mercier, F., Millery L., Pascual, A., Ravichandran, M., Shillington, F., Snaith, H., Strub, P.T., Vandermark, D., Vignudelli, S., Wilkin, J., Woodworth, P., Zavala-Garay, J., 2009. The role of altimetry in coastal observing systems, in: Hall, J., Harrison, D.E., Stammer, D. (Eds.), Proceedings of OceanObs'09: Sustained Ocean Observations and Information for Society, Venice, Italy.

Cipollini, P., Benveniste, J., Birol, F., Fernandes, M. J., Obligis, E., Passaro, M. Strub, P. T., Valladeau, G., Vignudelli, S., Wilkin J., 2017. Satellite altimetry in coastal regions, in: Stammer, D., Cazenave, A. (Eds.), Satellite Altimetry Over Oceans and Land Surfaces, CRC Press, pp. 343-380. ISBN: 9781498743457.

780 Coastal and Hydrology Altimetry product (PISTACH) handbook, SALP-MU-P-OP16031-CN 01/00, edition 1.0, October 2010. M., 2017. A new glider-compatible optical sensor for dissolved organic matter 
measurements: Test case from the NW Mediterranean Sea. Frontiers Mar. Sci. 4, 89. doi: 10.3389/fmars.2017.00089.

786 Declerck, A., Ourmières, Y., Molcard, A., 2016. Assessment of the coastal dynamics in a nested zoom and feedback on the boundary current: The North-Western Mediterranean Sea case. Ocean Dynam. 66, 1529-1542. doi: 10.1007/s10236-

Deng, X., Featherstone, W., Hwang, C., 2002. Estimation of contamination of ERS-2 and POSEIDON satellite radar altimetry close to the coasts of Australia. Mar. Geod. 25, 249-271.

Deng, X, Featherstone, W.E., 2006. A coastal retracking system for satellite radar 794 altimeter waveforms: Application to ERS-2 around Australia. J. Geophys. Res. 111, C06012. doi:10.1029/2005JC003039.

Desportes, C., Obligis, E., Eymard, L., 2010. One-dimensional variational retrieval of 797 the wet tropospheric correction for altimetry in coastal regions. IEEE Trans. Geosci. Remote Sens. 48(3), 1001-1008.

Dinardo, S., Fenoglio, L., Buchhaupt, C., Becker, M., Scharroo, R., Joana F., 800 Benveniste, J., 2017. Coastal SAR and PLRM altimetry in German Bight and West Baltic Sea. Adv. Space Res. 62(6), 1371-1404.

802 Doglioli A., 2015. Observing submesoscale coupling at high resolution, OSCAHR 803 cruise, RV Téthys II, http://dx.doi.org/10.17600/15008800.

804 Elipot, S., Gille, S.T., 2009. Estimates of wind energy input to the Ekman layer in the 805 Southern Ocean from surface drifter data. J. Geophys. Res. 114, C06003. 
806 Fernandes, M.J., Lázaro, C., Ablain, M., Pires, N., 2015. Improved wet path delays 807 for all ESA and reference altimetric missions. Remote Sens. Environ. 169, 50808 74.

809 Fernandes M.J., Lázaro, C., 2016. GPD+ wet tropospheric corrections for CryoSat-2 $810 \quad$ and GFO altimetry missions. Remote Sens. 8(10), 851.

811 Forget, P., Saillard, M., Broche, P., 2006. Observations of the sea surface by coherent 812 L band radar at low grazing angles in a nearshore environment. J. Geophys. Res. 111(C0), $9015-9028$.

814 Fu, L.-L., Chelton, D.B., 2001. Large-scale ocean circulation, in: Fu, L.-L., 815 Cazenave, A. (Eds.), Satellite Altimetry and Earth Sciences: A Handbook for 816 Techniques and Applications. Academic Press, San Diego, p. 423, 133-16.

817 Fu, L.-L., Chelton, D.B., Le Traon, P.-Y., Morrow, R., 2010. Eddy dynamics from 818 satellite altimetry. $\quad$ Oceanography. $\quad 23(4), \quad 14-25$. http://dx.doi.org/10.5670/oceanog.2010.02.

820 Fu, L.-L., Ferrari, R., 2008. Observing oceanic submesoscale processes from space. Eos Transactions AGU, 89(48), 488-488. doi: 10.1029/2008EO480003.

822 Gomez-Enri, J., Cipollini, P., Gommenginger, C., Martin Puig, C., Vignudelli, S., Woodworth, P., Benveniste, J.,Villares, P., 2009. Improving coastal altimeter products by a new retracking approach. Proc. SPIE-Remote Sens. Ocean, Sea Ice, and Large Water Regions, 7473.

826 Gula, J., Molemaker, M.J., McWilliams, J.C., 2014. Submesoscale cold filaments in 827 the Gulf Stream. J. Phys. Oceanogr. 44, 2617-43. 
828 Grilli, F., Pinardi, N., 1998. The computation of Rossby radii between external 829 forcing mechanisms and internal of deformation for the Mediterranean Sea. $830 \quad$ MTPNews, 6(4).

831 Hallberg, R., 2013. Using a resolution function to regulate parameterizations of 832 oceanic mesoscale eddy effects. Ocean Model. 72, 92-103. doi: $833 \quad$ 10.1016/j.ocemod.2013.08.007.

834 Heslop, E.E., Sánchez-Román, A., Pascual, A., Rodríguez, D., Reeve, K.A., Faugère, 835 Y., Raynal, M., 2017. Sentinel-3A views ocean variability more accurately at 836

Hu, Z.H., Petrenko, A.A., Doglioli, A.M., Dekeyser, I., 2011. Numerical study of eddy generation in the western part of the Gulf of Lion. J. Geophys. Res. 116, C12030. doi:10.1029/2011JC007074.

841 Huthnance, M.J., 1995. Circulation, exchange and water masses at the ocean margin: 842 The role of physical processes at the shelf edge. Prog. Oceanogr. 35, 353-431.

843 Imel, D., 1994. Evaluation of the TOPEX/POSEIDON dual-frequency ionosphere 844 correction. J. Geophys. Res. 99, 24895-24906.

845 Jebri, F., Zakardjian, B., Birol, F., Bouffard, J., Jullion, L., Sammari, C., 2017. 846 Interannual variations of surface currents and transports in the Sicily Channel 847 derived from coastal altimetry. J. Geophys. Res. Oceans. 122, 8330-8353.

848 JPL OurOcean Project, 2010. GHRSST Level 4 G1SST Global Foundation Sea 849 Surface Temperature Analysis. Ver. 1. PO.DAAC, CA, USA. 850 http://dx.doi.org/10.5067/GHG1S-4FP01 (accessed 24 May 2017). 
852 Lagerloef, G.S.E., Mitchum, G.T., Lukas, R.B., Niiler, P.P., 1999. Tropical Pacific 853 near-surface currents estimated from altimeter, wind, and drifter data. J. 854 Geophys. Res. 104(C10), 23313-23326.

855 Lehahn, Y., d'Ovidio, F., Ley, M., Heifetz, E., 2007. Stirring of the Northeast 856 Atlantic spring bloom: A Lagrangian analysis based on multi-satellite data. J. $857 \quad$ Geophys. Res. Ocean. 112, C08005.

858 Levy, M., Martin A., 2013. The influence of mesoscale and submesoscale 859 heterogeneity on ocean biogeochemical reactions. Glob. Biogeochem. Cycles. $860 \quad 27,1139-50$.

861 Mahadevan, A., 2016. The impact of submesoscale physics on primary productivity 862 of plankton. Annu. Rev. Mar. Sci. 8, 161-184.

Marmain, J., Molcard, A., Forget, P., Barth, A., Ourmières, Y., 2014. Assimilation of 864 HF radar surface currents to optimize forcing in the Northwestern Mediterranean Sea. Nonlin. Processes Geophy. 21, 659-675.

Marrec, P., Doglioli, A.M., Grégori, G., Dugenne, M., Della Penna, A., Bhairy, N., Cariou, T., Hélias Nunige, S., Lahbib, S., Rougier, G., Wagener, T., Thyssen, M., 2018. Coupling physics and biogeochemistry thanks to high resolution observations of the phytoplankton community structure in the North-Western Mediterranean Sea. Biogeosciences Discuss. https://doi.org/10.5194/bg-2017McGillicuddy, D.J., Robinson, A.R., Siegel, D.A., Jannasch, H.W., Johnson, R., Dickey, T.D., McNeil, J., Michaels, A.F., Knap, A.H., 1998. Influence of mesoscale eddies on new production in the Sargasso Sea. Nature. 394, 263-265. 
875 Millot, C., 1999. Circulation in the Western Mediterranean Sea. J. Mar. Syst. 20, 876 $423-442$.

877 Millot, C., 1991. Mesoscale and seasonal variabilities of the circulation in the 878 Western Mediterranean. Dyn. Atm. Oceans, 15, 179-214.

879 Millot C., TaupierLetage, I., 2005. Circulation in the Mediterranean Sea. The $880 \quad$ Handbook Environ. Chem. K, 29-66. doi:10.1007/b107143.

881 Morrow, R., Carret, A., Birol, F., Nino, F., Valladeau, G., Boy, F., Bachelier, C., 882 883 Zakardjian, B., 2017. Observability of fine-scale ocean dynamics in the 884 Northwestern Mediterranean Sea. Ocean Sci. 13, 13-29. 884 https://doi.org/10.5194/os-13-13-2017.

885

Muller-Karger, F.E., Varela, R., Thunell, R., Luerssen, R., Hu, C., Walsh, J.J., 2005. The importance of continental margins in the global carbon cycle. Geophys. Res. Lett. 32, L01602. doi:10.1029/2004GL021346.

Nencioli, F., d'Ovidio, F., Doglioli, A.M., Petrenko, A.A., 2013. In situ estimates of submesoscale horizontal eddy diffusivity across an ocean front. J. Geophys. Res. Oceans. 118, 7066-7080. doi:10.1002/2013JC009252.

Palacz, A.P., Pearlman, J., Simmons, S., Hill, K., Miloslavich, P., Telszewski, M., Sloyan, B., Pearlman, F., Bourassa, M., 2017. Report of the workshop on the Implementation of Multi-disciplinary Sustained Ocean Observations (IMSOO). Global Ocean Observing System (GOOS) Report No. 223, http://www.goosocean.org/imsoo-report.

Pascual, A., Bouffard, J., Ruiz, S., Buongiorno Nardelli, B., Vidal-Vijande, E., Escudier, R., 2013. Recent improvements in mesoscale characterization of the 

observational approaches. Sci. Mar. 77, 19-36. doi: 10.3989/scimar.03740.15a.

900

901

902

903

904

905

906

907

Pascual, A., Lana, A., Troupin, C., Ruiz, S., Faugère, Y., Escudier, R., Tintoré, J., 2015. Assessing SARAL data in the coastal zone: Comparisons with HF radar observations. Mar. Geod. 38, sup1, 260-276.

Pascual, A., Ruiz, S., Olita, A., Troupin, C., Claret, M., Casas, B., Mourre, B., Poulain, P-M., Tovar-Sanchez, A., Capet, A., Mason, E., Allen, J.T., Mahadevan, A., Tintoré, J., 2017. A multiplatform experiment to unravel meso- and submesoscale processes in an intense front (AlborEx). Frontiers Mar. Sci. 4, 39. doi: 10.3389/fmars.2017.00039.

Pascual, A., Ruiz, S., Tintore', J., 2010. Combining new and conventional sensors to study the Balearic current. Sea Technol. 51(7), 32-36.

Passaro, M., Cipollini, P., Vignudelli, S., Graham, D., Quartly, H., Snaith, M., 2014. ALES: A multi-mission adaptive subwaveform retracker for coastal and open ocean altimetry. Remote Sens. Environ. 145, 173-189. ISSN 0034-4257, https://doi.org/10.1016/j.rse.2014.02.008.

Passaro, M., Rose, S.K., Andersen, O.B., Boergens, E., Calafat, F.M., Dettmering, D., Benveniste, J., 2018. ALES+: Adapting a homogenous ocean retracker for satellite altimetry to sea ice leads, coastal and inland waters. Remote Sens. Environ. 211 456-471. ISSN 0034-4257, https://doi.org/10.1016/j.rse.2018.02.074.

Petrenko, A., 2003. Variability of circulation features in the Gulf of Lions NW Mediterranean Sea: Importance of inertial current. Oceanol. Acta. 26, 323-338. 
921 Pires, N., Fernandes, M.J., Gommenginger, C., Scharroo, R., 2016. A conceptually

922

923

924

925

926

927

928

929

930

931

932

933

934

935

936

937

938

939

940

941

942 simple modeling approach for Jason-1 sea state bias correction based on 3 parameters exclusively derived from altimetric information. Remote Sens. 8(7), 576.

Piterbarg, L., Taillandier, V., Griffa, A., 2014. Investigating frontal variability from repeated glider transects in the Ligurian Current (North West Mediterranean Sea). J. Mar. Syst. 129, 381-395. doi: 10.1016/j.jmarsys.2013.08.003.

Poisson, J.C., Quartly, G.D., Kurekin, A., Thibaut, P., Hoang, D., Nencioli, F., 2018. Development of an ENVISAT altimetry processor providing sea level continuity between open ocean and Arctic leads. IEEE Trans. Geosci. Remote Sens. 1-21.

Pond, S., Pickard, G., 2nd Edition 1986. Introductory Dynamical Oceanogrpahy, Pergamon Press Sydney. ISBN 0-08-028728-X

Powell, B.S., Leben, R. R., 2004. An optimal filter for geostrophic mesoscale currents from along-track satellite altimetry. J. Atmos. Oceanic Tech. 21(10), $1633-1642$.

Quentin, C., Barbin, Y., Bellomo, L., Forget, P., Gagelli, J., Grosdidier, S., Guerin, C.-A., Guihou, K., Marmain, J., Molcard, A., Zakardjian, B., Guterman, P., Bernardet, K., 2013. HF radar in French Mediterranean Sea: An element of MOOSE Mediterranean Ocean Observing System on Environment, OCOSS'2013 Proceedings, 25-30.

Ralph, E.A., Niiler, P.P., 1999. Wind-driven currents in the tropical Pacific. J. Phys. Oceanogr. 29, 2121-2129.

Ray, R. D., 2013. Precise comparisons of bottom-pressure and altimetric ocean tides, J. Geophys. Res. Oceans. 118, 4570-4584. doi:10.1002/jgrc.20336. 
945 Rio, M.-H., Hernandez, F., 2003. High-frequency response of wind-driven currents

946 measured by drifting buoys and altimetry over the world ocean. J. Geophys. Res. $947 \quad 108(\mathrm{C} 8), 3283-3301$.

948 Rio, M.-H., Poulain, P.-M., Pascual, A., Mauri, E., Larnicol, G., Santoleri, R., 2007.

949 A mean dynamic topography of the Mediterranean Sea computed from altimetric 950 data, in situ measurements and a general circulation model. J. Mar. Sys. 65, 484$951 \quad$ 508. doi:10.1016/j.jmarsys.2005.02.006.

952 Rio, M.H., Guinehut, S., Larnicol, G., 2011. New CNES-CLS09 global mean 953 dynamic topography computed from the combination of GRACE data, altimetry, 954 and in situ measurements. J. Geophys. Res. 116, C07018.

955 Rio, M.-H., 2012. Use of altimeter and wind data to detect the anomalous loss of 956 SVP-type drifter's drogue. J. Atmos. Oceanic Tech. 29, 1663-1674.

957 Rio, M.-H., Pascual, A., Poulain, P.-M., Menna, M., Barceló, B., Tintoré, J., 2014. 958 Computation of a new mean dynamic topography for the Mediterranean Sea 959 from model outputs, altimeter measurements and oceanographic in situ data. $960 \quad$ Ocean Sci. 10, 731-744. https://doi.org/10.5194/os-10-731-2014.

961 Ruiz, S., Garau, B., Martnez-Ledesma, M., Casas, B., Pascual, A., Vizoso, G., 962 Bouffard, J., Heslop, E., Alvarez, A. Testor, P., Tintoré, J., 2012. New 963 technologies for marine research: five years of glider activities at IMEDEA. Sci. $964 \quad$ Mar. $\quad 76, \quad$ p. $\quad 261270 . \quad 10.3989 /$ scimar.03622.191 965 http://scientiamarina.revistas.csic.es/index.php/scientiamarina/article/view/1372/ 966 1471. 
Ruiz, S., Pascual, A., Garau, B., Pujol, I., Tintoré, J., 2009. Vertical motion in the upper ocean from glider and altimetry data. Geophys. Res. Lett. 36:L14607. doi: 10.1029/2009GL038569. L14607.

Shcherbina, A.Y., D’Asaro, E.A., Lee, C.M., Klymak, J.M., Molemaker, M.J., McWilliams, J.C., 2013. Statistics of vertical vorticity, divergence, and strain in a developed submesoscale turbulence field. Geophys. Res. Lett. 40, 4706-11.

Smith, W.H.F., Strub, T., Miller, L., 2008. First coastal altimetry workshop. Eos Trans. AGU. 89(40), 380.

Ssalto/Duacs user handbook, 2016: (M)SLA and (M)ADT near-real-time and delayed-time products, Rep. SALP-MU-P-EA-21065-CLS, Aviso, RamonvilleSaint-Agne, France.

Stanev, E., Beckers, J.-M., Lancelot, C., Le Traon, P., Staneva, J., Peneva, P., Gregoire, M., 2002. Coastal-open ocean exchange. Black Sea examples from survey, satellite data and modelling. Estuar. Coast. Shelf Sci. 54, 601-620.

Strub, T., 2001. High-resolution ocean topography science requirements for coastal studies, in: Chelton, D.B. (Ed.), the Report of the High-resolution Ocean Topography Science Working Group meeting. College of Oceanic and Atmospheric Sciences, Oregon State University, Corvallis, p. 224.

Thomas, L.N., Tandon, A., Mahadevan, A., 2008. Submesoscale processes and dynamics. Ocean Model. Eddying Regime. 17-38.

Tran, N., Vandemark, D., Labroue, S., Feng, H., Chapron, B., Tolman, H.L., Lambin, J., Picot, N., 2010. Sea state bias in altimeter sea level estimates determined by combining wave model and satellite data. J. Geophys. Res. 115, C03020. 
990

991

992

993

994

995

996

997

998

999

1000

1001

1002

1003

1004

1005

1006

1007

1008

1009

1010

1011

1012

Troupin, C., Pascual, A., Valladeau, G., Pujol, I., Lana, A., Heslop, E., Ruiz, S., Torner, M., Picot, N., Tintoré, J., 2015. Illustration of the emerging capabilities of SARAL/AltiKa in the coastal zone using a multi-platform approach. Adv. Space Res. 55(1), 51-59.

Valladeau, G., Thibaut, P., Picard, B., Poisson, J.C., Tran, N., Picot, N., Guillot, A., 2015. Using SARAL/AltiKa to improve Ka-band altimeter measurements for coastal zones, hydrology and ice: The PEACHI prototype. Mar. Geod. 38(S1), 124-142. doi: 10.1080/01490419.2015.1020176.

Verron, J., Sengenes, P., Lambin, J., Noubel, J., Steunou, N., Guillot, A., Picot, N., Coutin-Faye, S., Sharma, R., Gairola, R.M., Murthy, R.D.V.A., Richman, J.G., Griffin, D., Pascual, A., Rémy, F., Gupta, P.K., 2015. The SARAL/AltiKa altimetry satellite mission, Mar. Geod. 38, sup1, 2-21. doi: 10.1080/01490419.2014.1000471.

Vignudelli, S., Cipollini, P., Roblou, L., Lyard, F., Gasparini, G.P., Manzella, G., Astraldi, M., 2005. Improved satellite altimetry in coastal systems: Case study of the Corsica Channel (Mediterranean Sea). Geophys. Res. Lett. 32, L07608. doi:10.1029/2005GL022602.

Vignudelli, S., Kostianoy, A., Cipollini, P., Benveniste, J., 2011. Coastal , DOIaltimetry. doi: 10.1007/978-3-642-12796-0.

Zakardjan, B., Prieur L., 1998. Biological and chemical signs of upward motions in permanent geostrophic fronts of the Western Mediterranean. J. Geophys. Res. $103,27849-27866$. 


\section{List of Figure Captions}

1014 Figure 11 OSCAHR cruise transects (in letters) showing MVP vertical salinity 1015 profiles (coloured rectangles), geo-located with altimetric tracks \#9 from Jason-2 and 1016 tracks \#429 and \#674 from SARAL. The main flow of the NC is shown with black

1017 arrows, the recirculation with the grey arrow and the Ligurian Sea area is highlighted 1018 by the red box.

1019 Figure 12 PEACHI high rate altimetry SLA editing and filtering for SARAL track $1020 \quad$ \#429. The black line corresponds to the AVISO $1 \mathrm{~Hz}$ track.

1021 Figure 13 RIO07 (a) and RIO14 (b) MDT overlapped by the derived mean current.

1022 Figure 14 Reference depth sensitivity study for transects A - B, D - A, G - I and H G. Different colours are associated with a different reference depths (in meters) considered in the vertical integration of MVP data, while PEACHI altimetry data are shown in black. The magenta line represents the MVP derived currents at the maximum operating depth. The shaded grey areas in transects $\mathrm{A}-\mathrm{B}$ and $\mathrm{D}-\mathrm{A}$ correspond to $20 \mathrm{~km}$ from the coast.

Figure 5 Mean (blue) and standard deviation (yellow) of the current differences between PEACHI and MVP.

1031 Figure 6 Geographical plot of the differences (coloured dots) of the surface across 1032 track current ADCP-MVP. The vectors are related to the cross-track component of 1033 the ADCP current at $270 \mathrm{~m}$ depth.

1034 Figure 7 Comparison between MVP (magenta) and ADCP currents (raw data in thin blue, filtered and smoothed data in dashed thick blue) for each transect.

Figure 15 PEACHI Altimetry (grey for SLA+RIO07 and red for adaptive retracking, cyan for Red3 retracking and green for MLE4 retracking for SLA+RIO14) vs AVISO altimetry (light grey for SLA+RIO07 and grey for SLA+RIO14) vs in situ (magenta for MVP, blue for ADCP). Different markers for both AVISO and PEACHI altimetry are related to elevations and currents computed with a different MDT (crosses for RIO07 and diamonds for RIO14). First column reports track geolocation, second column reports ADT $(\mathrm{m})$ vs Latitude and third column reports satellite across track current (ms-1) derived from ADT computed adding RIO14 to SLA vs Latitude together with in situ derived current vs Latitude. The distance to the coast is also reported in Kilometres.

Figure 16 Surface circulation pattern derived from in situ (magenta for MVP and blue for ADCP) and PEACHI altimetry data (black). SST data is also shown with a Spatial Resolution of $0.062^{\circ}$ (Latitude) x $0.062^{\circ}$ (Longitude) and temporal resolution of 1 day. The SST maps is an average over the OSCAHR cruise time period $\left(29^{\text {th }}\right.$ October 2015 to $6^{\text {th }}$ November 2015). White arrows depict the surface oceanographic features reported also in Figure 10 vertical profiles.

1055

Figure 17 MVP Salinity and temperature vertical profiles. The oceanographic features are reported with white arrows. 